NBER WORKING PAPER SERIES

\title{
THE INTERNATIONAL TRANSMISSION OF LOCAL ECONOMIC SHOCKS THROUGH
} MIGRANT NETWORKS

\author{
María Esther Caballero \\ Brian Cadena \\ Brian K. Kovak \\ Working Paper 28696 \\ http://www.nber.org/papers/w28696 \\ NATIONAL BUREAU OF ECONOMIC RESEARCH \\ 1050 Massachusetts Avenue \\ Cambridge, MA 02138 \\ April 2021
}

This work has benefited from research, administrative, and computing support provided by the University of Colorado Population Center (CUPC; Project 2P2CHD066613-06), funded by the Eunice Kennedy Shriver National Institute of Child Health and Human Development (NICHD). The content is solely the responsibility of the authors and does not necessarily represent the official views of CUPC or NICHD. This research was funded in part by a grant from the Russell Sage Foundation's Race, Ethnicity, and Immigration Program. Laura Goyeneche provided excellent research assistance. Special thanks to Ambassador Juan Carlos Mendoza, Edith Soto Ramirez, Mark Hugo Lopez, Caue Dobbin, and Melanie Morten for assistance with data access and interpretation. Thanks to Treb Allen, Caue Dobbin, Chloe East, Ethan Lewis, Philip Luck, Hani Mansour, Craig McIntosh, Melanie Morten, Andrea Velasquez, and various seminar participants for helpful comments. Remaining errors are our own. The views expressed herein are those of the authors and do not necessarily reflect the views of the National Bureau of Economic Research.

NBER working papers are circulated for discussion and comment purposes. They have not been peer-reviewed or been subject to the review by the NBER Board of Directors that accompanies official NBER publications.

(C) 2021 by María Esther Caballero, Brian Cadena, and Brian K. Kovak. All rights reserved. Short sections of text, not to exceed two paragraphs, may be quoted without explicit permission provided that full credit, including $(\mathrm{C}$ notice, is given to the source. 
The International Transmission of Local Economic Shocks Through Migrant Networks María Esther Caballero, Brian Cadena, and Brian K. Kovak

NBER Working Paper No. 28696

April 2021

JEL No. F22,J21,J23,J61,R23

\begin{abstract}
Using newly validated data on geographic migration networks, we study how labor demand shocks in the United States propagate across the border with Mexico. We show that the large exogenous decline in US employment brought about by the Great Recession affected demographic and economic outcomes in Mexican communities that were highly connected to the most affected markets in the US. In the Mexican locations with strong initial ties to the hardest hit US migrant destinations, return migration increased, emigration decreased, and remittance receipt declined. These changes significantly increased local employment and hours worked, but wages were unaffected. Investment in durable goods and children's education also slowed in these communities. These findings document the effects in Mexico when potential migrants lose access to a strong US labor market, providing insight regarding the potential impacts of stricter US migration restrictions.

María Esther Caballero

H. John Heinz III College

Carnegie Mellon University

4800 Forbes Avenue, HBH 3018

Pittsburgh, PA 15213

mcaballe@cmu.edu

Brian Cadena

Department of Economics

University of Colorado Boulder

256 UCB

Boulder, CO 80309-0256

http://spot.colorado.edu/ cadenab/

brian.cadena@colorado.edu

Brian K. Kovak

H. John Heinz III College

Carnegie Mellon University

4800 Forbes Avenue, HBH 3012

Pittsburgh, PA 15213

and NBER

bkovak@cmu.edu
\end{abstract}




\section{Introduction}

Goods trade and capital flows are well-studied economic mechanisms that integrate markets across international borders, but international migration represents another potentially equilibrating force (Chiswick and Hatton 2003). International migration is driven partly by economic incentives, with migrants responding to relative economic conditions in sending and receiving locations. Research suggests that potential migrants choose destinations with higher expected earnings, and their choices affect the size and composition of the labor force in source and destination communities (Hanson and Spilimbergo 1999, Borjas 2001, Cadena 2013, Cadena and Kovak 2016). This earnings-maximizing behavior implies that local labor market conditions in potential destinations will affect demographic and economic outcomes in sending locations by changing both migration choices and the remittance behavior of existing migrants.

In this paper, we study how changes in US labor demand affect migration, demographic, and economic outcomes in migration-network-connected communities in Mexico. The United States is by far the most important destination for migrants from Mexico, as 98 percent of Mexicans living abroad are in the US and approximately 10 percent of the Mexican-born population lives in the United States. ${ }^{1}$ Changes in US labor demand should thus have important consequences in Mexican sending communities. We focus on the effects of US labor demand declines during the Great Recession and show that these demand shocks affect outcomes across an international border in Mexican sending areas with strong ties to the hardest-hit US local labor markets. Our focus on sending communities contrasts with that of most of the literature on the economics of Mexico-US migration, which primarily evaluates the impacts of Mexican migration on US destination markets. ${ }^{2}$ We know relatively little about the effects of the US labor market on outcomes in Mexico because of the lack of detailed information connecting migrants' sources and destinations at the sub-national level.

\footnotetext{
${ }^{1}$ Numbers living in the US and in other countries are available in Secretaría de Relaciones Exteriores (2015). Population numbers for 2010 and 2015 are available at https://www.inegi.org.mx/temas/estructura/.

${ }^{2}$ See National Academies of Sciences, Engineering, and Medicine (2017) for a survey of the literature on the effects of immigration on earnings, employment, and wages in destination countries, and Mishra (2014) for a survey of the literature on the effects of emigration on wages in source countries.
} 
We overcome this challenge using newly validated administrative data from the Matrícula Consular de Alta Seguridad (MCAS) identification card program. These data measure the distribution of US commuting zones chosen by migrants from each Mexican municipio (similar to a US county). This network measure has far more geographic detail than is available in other data sources, allowing us to observe each Mexican sending community's ties to each US local labor market. ${ }^{3}$ We derive a reduced-form estimating equation and shock measure from a simple location choice model, which shows how to leverage two key sources of variation: the heterogeneity across US commuting zones in employment declines during the Great Recession and differences in migration network connections between each Mexican municipio and each US destination. The resulting research design compares the change in outcomes between source municipios whose migrants face larger and smaller effective declines in US employment given their source location's mix of US destinations.

In order for this analysis to have a causal interpretation, a municipio's network-weighted US demand shock must be uncorrelated with other factors affecting its demographic and economic outcomes. This exogeneity assumption is likely to hold in part because the relevant demand shocks for each municipio occur in another country (the US) and are thus unlikely to be related to other changes in Mexican source communities. To strengthen the causal interpretation, we include Mexican state fixed effects so that we compare only geographically proximate municipios, and we allow for differential trends based on pre-existing characteristics of the source community. Further, we follow the model-motivated estimation strategy by controlling for contemporaneous changes in observable source-level characteristics such as drug-related violence and local trade shocks, and networkweighted averages of destination-level changes in local immigration enforcement policy. The results are robust to the inclusion of these controls, bolstering the interpretation of the key coefficient as the causal effect of declining US labor demand on Mexican source community outcomes.

Using Mexican Census data we find that source communities with strong initial ties to the US destinations hardest-hit by the Recession experienced faster population growth, driven in large part

\footnotetext{
${ }^{3}$ Caballero, Cadena and Kovak (2018) confirm the quality and representativeness of the MCAS data by comparing it against high quality household survey data. Other papers using various versions of the MCAS data include Albert and Monras (2019), Allen, Dobbin and Morten (2019), and Tian, Caballero and Kovak (2020).
} 
by increased return migration and decreased emigration. The change in migration also substantially increased the share of the local workforce that is male in these source communities. Beyond the movement of people, we also find a decline in the likelihood that households receive remittances in Mexican sources facing larger US labor demand declines.

These changes in population size and composition directly lead to a substantial increase in the size of the local labor force. Further, the loss of US remittance income creates an incentive for additional household members to enter the labor force. Using data from the Mexican Economic Census, we examine the impact of these changes on municipio-level labor market outcomes. As expected, we find clear evidence of an expansion in labor supply, with source communities facing the largest declines in US employment opportunities seeing increases in employment and total hours worked, especially among women. We reinforce this result with descriptive evidence showing that the relationship between labor supply and US labor demand shocks appears only in households with migrants in the US. Interestingly, we find no evidence that this expansion of labor supply led to a decrease in local wages, a result that is consistent with much of the literature on the effect of immigration on host labor markets. ${ }^{4}$ We then document the effects of declining US labor demand on household investment behavior, both in durable goods and human capital. We find that municipios facing larger US job losses see slower growth in the ownership of televisions (and minimal estimated effects on other appliances) and that children in these communities are less likely to remain in school, especially at late primary school ages.

Taken together, these results demonstrate that migrant networks transmit changes in US local labor demand across the southern border with Mexico, leading to significant effects on a wide variety of outcomes in sending areas. Further, because our analysis focuses on job loss among migrants, the results show how losing access to US employment affects economic outcomes in Mexican migrantsending communities. Policymakers have recently proposed limiting some migrants' ability to work in the US through other means, such as mandatory nationwide E-Verify, which would require firms to check a nationwide electronic database to see whether a job applicant has legal authorization

\footnotetext{
${ }^{4}$ See National Academies of Sciences, Engineering, and Medicine (2017) for a thorough literature review.
} 
to work before hiring them. ${ }^{5}$ Thus, in addition to documenting the impacts of the US Great Recession across Mexican communities, our findings provide insight regarding the potential impacts of migration restrictions currently under consideration.

This paper contributes to multiple strands of literature. First, as mentioned above, many papers find that international migrants' location choices respond to local labor market conditions. Borjas (2001) simulated how foreign-born workers' location choices might equalize native workers' wages across regional labor markets in the destination country, and Cadena and Kovak (2016) empirically measure these equalizing effects, showing that a metropolitan area's local population of Mexicanborn workers with no more than a high school degree was strongly responsive to changes in local labor demand during the Great Recession. ${ }^{6}$ Our results here reinforce the idea that, in addition to internal migration, international migration also contributes to the reallocation of migrants across US markets. If this behavior applies more generally, it poses an additional challenge in identifying the effects of immigration on destination markets that is not addressed by standard enclave-based instruments. $^{7}$ These instruments are designed to address endogenous sorting across destinations among those who choose to migrate. Our results imply that local labor demand conditions in the relevant subset of potential migrant destinations influence the choice of whether to migrate internationally, raising the likelihood of reverse causality between destination labor market conditions and the source-level migrant flows used to construct enclave-based instruments.

Second, this study expands our understanding of the role networks play in driving international migration. Larger numbers of migrants from a sending community increase the likelihood

\footnotetext{
${ }^{5}$ Related papers document population responses to Arizona's statewide E-Verify policy, with migration results similar to what we find in this paper (Bohn, Lofstrom and Raphael 2014, Caballero et al. 2018). The Comprehensive Immigration Reform Bill that passed the US Senate in 2013 included a mandatory national E-Verify provision. More recently, in February 2021, Senators Romney and Cotton proposed universal E-Verify as a condition for raising the federal minimum wage to $\$ 10$ (King 2021).

${ }^{6}$ Clemens (2017) also exploits the geographic variation in unemployment during the Great Recession to evaluate the effects of Mexican migrant labor supply on native employment in the US agricultural sector, finding that foreignworker competition in a recessionary environment caused a negative but small impact on native employment in this sector.

${ }^{7}$ This type of instrument was first introduced by Altonji and Card (1991), based on results in Bartel (1989). Although some papers attempt to identify specific source-level shocks to predict aggregate inflows from each source(Llull 2018), most papers simply assume that the total inflow from each source is exogenous. Jaeger, Ruist and Stuhler (2019) provide a more complete overview of this literature and offer an independent critique of the instrument based on the dynamics of adjustment to previous waves of migration.
} 
of subsequent migration by lowering migration costs, especially for those with relatively low levels of education (Massey and Espinosa 1997, Winters, de Janvry and Sadoulet 2001, McKenzie and Rapoport 2007, Garip and Asad 2016). Migrant networks are also important in determining migrants' destination locations, occupational choices, and labor market success (Munshi 2003, Edin, Fredriksson and Åslund 2003). We extend this literature by showing that migrant networks also determine how source-location outcomes are affected by differences in foreign demand changes across locations within a single destination country.

Third, our results relate to the substantial literature examining the effects of migration on family members left behind. As summarized nicely in Antman (2013), demand shocks at the destination are one of two commonly used instruments in this body of work. ${ }^{8}$ Relative to this literature, our analysis is distinct in two ways. First, we consider the effects of a decline in destination labor market opportunities and thus the effects of increased return migration, deferred emigration, and a decline in remittances. We therefore examine the inverse of typical studies in this literature, which focus on the effects of emigration. The second distinction is that we consider outcomes at the municipio level rather than the household level. This unit of analysis allows us to measure the overall effects on local markets including any cross-household spillovers resulting from spatial equilibrium and allows us to use a wide array of high-quality survey and administrative data sources to measure municipio-level outcomes.

Finally, we extend the literature considering how changes in destination-market labor demand or policies affect sending communities. Caballero et al. (2018) and Allen et al. (2019) use MCAS migration network data to show that migration enforcement reduces international migration between affected sources and destinations, and Caballero (2020) uses the rollout of the Secure Communities program to show that local migration enforcement at the destination reduces school enrollment in the most affected sources. The studies most closely related to the present paper consider the effects of US labor demand conditions on economic outcomes in Mexico, such as occupational choices, entrepreneurship, inequality, and education (McKenzie and Rapoport 2007, Schnabl 2007, Fajardo,

\footnotetext{
${ }^{8}$ Examples include Antman (2011) and Cortes (2015).
} 
Gutierrez and Larreguy 2017, Conover, Khamis and Pearlman 2021). ${ }^{9}$ We make a number of contributions relative to this prior literature. First, our simple location choice model clarifies how to combine information on migration network connections, variation in labor demand across US destinations, and source locations' exposure to the US labor market in an internally consistent research design. We also use uniquely detailed geographic information in the US and Mexico. This detail allows us to measure shocks to well-defined US local labor markets (commuting zones) and to compare outcomes among municipios within the same Mexican state, strengthening causal identification. Further, by focusing on municipios, we are able to examine the impact of US job loss on a wide variety of outcomes using reliable full-count tabulations from multiple Mexican datasets.

Another set of papers considers the effects of foreign demand on sending communities in countries other than the US and Mexico. Yang (2008) and Theoharides (2018) combine variation in the historical destination countries of migrants from different source communities within the Philippines with destination-level shocks. ${ }^{10}$ Our approach is similar, but it benefits from using variation in labor demand across migrant destinations within the same country (the US). Because each municipio sends migrants primarily to the US, our analysis is robust to other nationwide changes to the attractiveness of living in the destination, including immigration enforcement or visa availability. In our context, there is also less scope for selection into migration to particular destinations based on unobserved source characteristics that may affect the outcomes - migrant sources connected to San Antonio vs. Chicago are likely more similar to each other than are sources sending migrants to Germany vs. Qatar. Dinkelman and Mariotti (2016) and Dinkelman, Kumchulesi and Mariotti (2017) leverage the exogenous imposition and later lifting of emigration restrictions in Malawi to yield highly credible estimates of the causal effects of remittances on educational attainment, capital accumulation, and the structure of rural labor markets in migrant sources. In the absence of such policy changes in the Mexican context, our approach combines shocks across migrant destinations

\footnotetext{
${ }^{9}$ In historical contexts, Kosack (forthcoming) studies the effect of differential access to the US Bracero program on Mexican human capital investment, and Brum (2019) studies the effects of economic shocks in US counties on migration from Italian municipalities.

${ }^{10}$ Yang (2008) uses exchange rate changes that alter the domestic value of remittances from different source countries, and Theoharides (2018) uses the overall flow of migrants from the Philippines to each source country.
} 
with persistent geographic migrant networks to generate similar variation across migrant sources in access to higher-paying foreign labor markets.

The remainder of the paper is organized as follows. Section 2 introduces our novel dataset and demonstrates that historical settlement patterns led to substantial variation in how Mexican source municipios experienced the US Great Recession. Section 3 provides the location choice model that leads to our estimation strategy. Section 4 discusses the variety of US and Mexican data sources we compile to execute our analysis. Section 5 shows that larger negative labor demand shocks in the US led to increases in source population through both increased return migration decreased emigration, as well as a decline in the share of households receiving remittances. Section 6 then demonstrates that these changes increased local employment without decreasing average wages but that they led to a slowdown in local appliance purchases and a reduction in school enrollment among children. Section 7 concludes.

\section{Motivation and Context}

The central analysis in this paper is based on the idea that potential migrants from different Mexican source communities face different changes in US labor demand. This variation comes from two sources: 1) changes in local labor demand were different across US local labor markets, and 2) migrant-sending communities in Mexico have historical ties to different sets of destinations within the US. In this section, we provide descriptive evidence supporting each of these two key facts.

\subsection{Geographic Variation in Job Loss During the Great Recession}

Identifying labor demand shocks is generally challenging because observed changes in employment and earnings normally reflect changes in both labor demand and labor supply. To overcome this challenge, we take advantage of the unique environment provided by the Great Recession. During this time period, there was a dramatic reduction in hiring and a large increase in layoffs, but wages did not fall substantially along with employment (Rothstein 2012, Daly, Hobijn and Wiles 2012). 
This pattern suggests that the labor market adjusted primarily along the employment margin rather than through wage reductions. Given downward-rigid wages, one can measure local labor demand shocks over the Great Recession period (2006-2010) using only changes in payroll employment (Cadena and Kovak 2016, Clemens 2017). ${ }^{11}$ Moreover, as emphasized in Section 3, our focus on outcomes in Mexico mitigates identification concerns that would have otherwise arisen had we focused on US outcomes.

Figure 1 shows the substantial variation in employment changes from 2006-2010 across US local labor markets. This map uses data from the County Business Patterns (CBP) and the American Community Surveys (ACS) to show changes in employment in US Commuting Zones (CZ), which define destination labor markets throughout the paper. ${ }^{12}$ We account for the industry mix of Mexican workers' US employment by measuring the relevant employment change in each commuting zone $d$ as $\sum_{i} \frac{E m p_{i d}^{M}}{E m p_{d}^{M}}\left(\frac{E m p_{i d}^{2010}-E m p_{i d}^{2006}}{E m p_{i d}^{2006}}\right)$, where $E m p_{i d}^{\text {year }}$ is employment in industry $i$ in destination commuting zone $d$ and $\frac{E m p_{i d}^{M}}{E m p_{d}^{M}}$ is the share of Mexican-born workers in commuting zone $d$ working in industry $i$ in 2006. ${ }^{13}$ This measure accounts for the fact that Mexican-born workers are disproportionately represented in industries that are especially sensitive to the business cycle, such as construction. ${ }^{14}$ As Figure 1 shows, although most commuting zones experienced a decline in employment, there was substantial variation, with a 14 percent decline at the 25 th percentile and no change at the 75 th percentile.

\footnotetext{
${ }^{11}$ If wages are perfectly downward rigid, then negative shifts in labor demand are perfectly captured by changes in employment. However, our approach is valid whenever the change in local labor demand is proportional to observed change in employment.

${ }^{12}$ We aggregate county-level information to the CZ level using the crosswalk in Dorn (2009) (https://www. ddorn. net/data.htm (file E7)), making manual adjustments to maintain consistent county boundaries over time. Because the most disaggregated sample available in the ACS is the Public Use Micro Areas (PUMA), we use another crosswalk from Dorn (2009) to match PUMAS to commuting zones (https://www.ddorn. net/data.htm (file E5)).

${ }^{13}$ The CBP data provide employment counts for the universe of employment in covered private industries. We fill in employment changes for industries not covered by the CBP (including government and agriculture) and measure the CZ-specific share of Mexican individuals working in each industry using data from the 2006 American Community Survey (ACS) from IPUMS (Ruggles, Flood, Goeken, Grover, Meyer, Pacas and Sobek 2017). We observe 20 separately identifiable industries at the CZ level.

${ }^{14}$ The main results are qualitatively similar, however, when using unweighted CZ-level employment declines.
} 


\subsection{Matrículas Consulares de Alta Seguridad}

In addition to this spatial variation in US labor demand, we leverage variation in the destinations historically chosen by migrants from different Mexican source communities. We measure this variation using administrative tabulations from Mexico's Matrícula Consular de Alta Seguridad (MCAS) program, in which Mexican consulates issue identity cards to Mexican-born individuals living in the US. The cards, which provide a secure form of identification and verified current residence for banking and other purposes, are issued primarily to those without authorization to live and work in the US and who therefore cannot access other forms of identification. ${ }^{15}$ Caballero et al. (2018) validated the use of the MCAS data to measure the joint distribution of sending municipios in Mexico (similar to US counties) and receiving US states by comparing the MCAS data against well-known household surveys, finding close agreement among the data sources.

To examine the variation in US destinations for migrants from different source municipios, we use the MCAS data to calculate $\frac{m_{s d}}{\sum_{d^{\prime}} m_{s d^{\prime}}}$, i.e. the share of migrants born in source municipio $s$ who settled in destination commuting zone $d$ in 2006. We use data from 2006 because it is the first year the MCAS tabulations are available and because it is prior to the onset of the Great Recession. To calculate these shares at such a fine of a level of geography, we rely on a customized extract from the MCAS administrative database that captures Mexican-born individuals' birthplace and county of residence in the US. ${ }^{16}$ The publicly available tabulations used in Caballero et al. (2018), in contrast, report only Mexican migrants' state of residence in the US. We aggregate destination counties to the commuting zone $(\mathrm{CZ})$ level, continuing to treat $\mathrm{CZs}$ as separate local labor markets within the US.

\footnotetext{
${ }^{15}$ See Massey, Rugh and Pren (2010), Caballero et al. (2018), Albert and Monras (2019), and Allen et al. (2019) for examples of prior work using the MCAS data.

${ }^{16}$ See Appendix A-2 for details on matching geographic locations in the MCAS extract to municipios and counties. Special thanks to Melanie Morten for providing the specific version of the extract used in this study.
} 


\subsection{Migrants from Nearby Sources Settle in Distinct Destinations}

As a motivating example of the variation in migrant destinations, Figure 2 compares the destination distributions for two Mexican source municipios in the state of Guanajuato: Dolores Hidalgo and Jaral del Progreso. Our empirical analysis controls for Mexican state fixed effects, so we are especially interested in within-Mexican-state differences in chosen destinations. Despite these two source communities' close proximity to each other and thus roughly equal distances to each US labor market, there are large differences in the US destinations selected by migrants from these two municipios. Migrants from Dolores Hidalgo tend to concentrate in the commuting zones containing the main cities of Texas, while migrants from Jaral del Progreso concentrate in Chicago and the largest cities of California. As shown in Figure 1, the Texas cities faced particularly mild labor demand declines during the Great Recession, while southern California saw larger negative shocks. Thus, migrants from Jaral del Progreso experienced a larger effective decline in US labor demand than did migrants from Dolores Hidalgo.

\section{Theoretical Framework and Research Design}

To formalize the intuitive idea that potential migrants from different Mexican source locations experienced the US Great Recession differently, we use a location choice model in which Mexicanborn individuals can choose to live in Mexico or in one of many potential destinations in the US. Potential migrants benefit from living alongside others from their place of birth, a model feature motivated by the variation in geographic migrant networks documented in Figure 2. We use comparative statics from the model to derive a tractable and intuitive expression relating source municipio population growth to the change in US employment faced by potential migrants from each source. This expression motivates our reduced-form estimating equation and clarifies the set of potential confounding variables that must be controlled for in order to identify the causal effect of US labor demand shocks on Mexican outcomes. 


\subsection{Location Choice Model}

An individual $j$ from Mexican source community $s$ may choose to live in any destination $d$, including their municipio of birth $s$ or any of the potential US destination commuting zones. For simplicity, we assume costless migration and ignore internal migration within Mexico. Individual $j$ 's utility from choosing destination $d$ depends on three things: the common value $v_{d}$ of living in that location, which does not depend on the migrant's origin community, a network component reflecting the presence of prior migrants from the potential migrant's source $n_{s d}$, and an iid type-I extreme value shock $\eta_{j s d} .{ }^{17}$

$$
u_{j s d}=\alpha v_{d}+n_{s d}+\eta_{j s d}
$$

Because in the MCAS data we observe migrants' birth location rather than their location prior to migrating to the US, this expression is the utility of choosing destination $d$ for a person born in source $s$, irrespective of their current location. The probability that a person born in $s$ chooses to live in $d$ is then

$$
P_{s}(d)=\frac{\exp \left(\alpha v_{d}+n_{s d}\right)}{\sum_{d^{\prime}} \exp \left(\alpha v_{d^{\prime}}+n_{s d^{\prime}}\right)}
$$

We examine how population growth in each source municipio is affected by a set of shocks to the value of locating in the various potential destinations. Let $M_{s}$ be the number of people born in Mexican source $s$, and let $M_{s d}$ be the number of people born in source $s$ living in destination $d$. The population residing in $s$ is therefore $M_{s s}=M_{s} P_{s}(s)$, i.e. the number of people born in $s$ multiplied by the probability that a person born in $s$ stays in that location. Assume that the total number of people born in source $s\left(M_{s}\right)$ is invariant to changes in destination values (i.e. shocks do not affect mortality). As shown in Appendix A-1, taking the total derivative of $M_{s s}$ with respect to changes in values $v_{d}$ for all possible destinations and evaluating the changes in choice probabilities using (2) yields the following expression relating the proportional change in source $s$ population to

\footnotetext{
${ }^{17}$ The parameter $\alpha$ captures the importance of $v_{d}$ relative to the idiosyncratic shock, $\eta_{j s d}$. The inclusion of $\alpha$ is only relevant once we parameterize $v_{d}$ in equation (4).
} 
the shocks to the value of living in each potential location:

$$
\begin{aligned}
& \frac{d M_{s s}}{M_{s s}}=\alpha \xi_{s}\left[d v_{s}-\sum_{d \neq s} \varphi_{s d} d v_{d}\right] \\
& \text { where } \quad \xi_{s} \equiv\left(1-P_{s}(s)\right) \text { and } \varphi_{s d} \equiv \frac{P_{s}(d)}{1-P_{s}(s)}
\end{aligned}
$$

This expression is intuitive. The term $\xi_{s}$ is the share of people from source $s$ who had chosen to live in the US prior to the shock, i.e. the source's baseline exposure to the US labor market. The first term in square brackets is the change in the value of living in the source community. As its own conditions improve, it attracts more residents, and this effect is larger when there are more residents abroad to attract, i.e. when exposure is higher. The second term in square brackets captures the effects of changing conditions in the US as mediated through the migrant network $\left(n_{s d}\right.$ in $\left.(1)\right)$. This term is a proper weighted average of shocks in US destinations, where the weights, $\varphi_{s d}$, reflect the baseline distribution of migrants from $s$ across US destinations $(d \neq s)$. As conditions in the US labor markets to which source $s$ has existing network connections improve, more people move abroad, reducing municipio s's resident population.

To study how changes in labor demand across US destinations affected demographic and economic outcomes in Mexican source communities, we parameterize the value of living in each US destination commuting zone. The common value of living in US location $d(\neq s)$ depends on expected earnings and other factors such that

$$
v_{d}=w_{d} \cdot \operatorname{Pr}\left(e m p_{d}\right)+\Gamma_{d}
$$

where $w_{d}$ is the real wage and $\operatorname{Pr}\left(e m p_{d}\right)$ is the probability of employment, their product is expected earnings in location $d$, and $\Gamma_{d}$ captures other features affecting the attractiveness of destination $d$. We take the change in (4) holding $w_{d}$ fixed based on the wage rigidity observed during the Great 
Recession (discussed in Section 2), and plug it into (3), yielding the following expression.

$$
\frac{d M_{s s}}{M_{s s}}=\alpha \xi_{s} d v_{s}-\alpha \xi_{s}\left[\sum_{d \neq s} \varphi_{s d} w_{d} d \operatorname{Pr}\left(e m p_{d}\right)\right]+\alpha \xi_{s} \sum_{d \neq s} \varphi_{s d} d \Gamma_{d}+\nu_{s}
$$

This expression forms the basis of our reduced form estimation equation, which relates source municipio population growth to changes in the attractiveness of the source community $\left(d v_{s}\right)$, changes in employment probabilities across US destinations $\left(d \operatorname{Pr}\left(e m p_{d}\right)\right)$, and other changes affecting the attractiveness of particular destinations within the U.S $\left(d \Gamma_{d}\right) \cdot{ }^{18}$

\subsection{Estimating Equation}

To empirically operationalize (5) we must first define the change in expected earnings in each US destination in terms of observable quantities. We assume that i) the employment probability facing Mexican-born residents of $d$ is given by the employment to population ratio among the Mexican-born population, ii) the baseline employment probability for Mexicans is equal across US destinations, iii) job losses in a given industry and commuting zone are allocated with equal probability to Mexicanborn and US-born workers, and iv) the baseline real wage for Mexican workers is equal across US destinations. Given these assumptions (see Appendix A-1),

$$
\sum_{d \neq s} \varphi_{s d} w_{d} d \operatorname{Pr}\left(e m p_{d}\right)=w \gamma \sum_{d \neq s} \varphi_{s d} \sum_{i} \frac{E m p_{i d}^{M}}{E m p_{d}^{M}} \cdot \frac{d E m p_{i d}}{E m p_{i d}}
$$

where $w$ is the US wage and $\gamma$ is the baseline employment probability facing Mexican workers in the US, $E m p_{i d}$ is employment in industry $i$ in destination $d, E m p_{i d}^{M}$ is Mexican employment in $i$ and $d$, and $E m p_{d}^{M}$ is overall Mexican employment in $d .{ }^{19}$ This shock to expected earnings can be

\footnotetext{
${ }^{18}$ Note that we normalize $d \Gamma_{s}=0$, so the $d \Gamma_{d}$ for $d \neq s$ reflect changes in the attractiveness of US destination $d$ relative to staying in Mexico.

${ }^{19}$ See Appendix A-1 for a step-by-step derivation.
} 
written in the following form, which is helpful in interpreting its scale. ${ }^{20}$

$$
\gamma \sum_{d \neq s} \varphi_{s d} \sum_{i} \frac{E m p_{i d}^{M}}{E m p_{d}^{M}} \cdot \frac{d E m p_{i d}}{E m p_{i d}}=\frac{1}{\sum_{d^{\prime} \neq s} M_{s d^{\prime}}} \sum_{d \neq s} \frac{M_{s d}}{M_{d}} d E m p_{d}^{M}
$$

Note that $\varphi_{s d}$ has been replaced by the observed share of Mexican migrants from $s$ who reside in $d: M_{s d} /\left(\sum_{d^{\prime} \neq s} M_{s d^{\prime}}\right)$. Since $\sum_{d^{\prime} \neq s} M_{s d^{\prime}}$ is the total number of US migrants from $s$, the right side of (7) is the number of jobs lost (or gained) per migrant from $s$. We therefore interpret the US employment shocks faced by Mexican migrants in terms of US jobs lost per migrant from each source.

In addition to US employment shocks, (5) shows that source-municipio population growth is also affected by changes in amenities in the source municipio $\left(d v_{s}\right)$ or US destinations $\left(d \Gamma_{d}\right)$. We account for changes in source-municipio amenities in three ways. First, we include Mexican-state (entidad federal) fixed effects, $\phi_{e(s)}$ to account for changes in the value of living in one's home community that are common to municipios within the same Mexican state. Our identification strategy therefore relies on within-Mexican-state variation in US labor demand shocks, which comes from both the variation in the depth of recession shown in Figure 1 and within-state variation in network connections demonstrated in Figure 2. Second, we present specifications controlling for a vector $\Delta X_{s}$ of changes in municipio-level characteristics potentially affecting the attractiveness of each source, including changes in local homicide rates and trade shocks. Third, we present specifications including preRecession differences in outcome growth as additional explanatory variables to control for any unobserved changes in source-level amenities that vary persistently over time.

Equation (5) shows that changes in the attractiveness of destinations enter the expression in a weighted average, where the weights, $\varphi_{s d}$, are identical to those in the US employment shock measure. We therefore control for weighted averages of changes in CZ-level characteristics, $\Delta X_{d}$, including local immigrant enforcement measures and employment policies. Our results are robust to including or excluding these various source- and destination-level controls. ${ }^{21}$

\footnotetext{
${ }^{20}$ Thanks to Craig McIntosh for suggesting this interpretation of our shock measure. See Appendix A-1 for a detailed derivation.

${ }^{21}$ Table 2 presents specifications with and without the various controls, and Appendix Section A-3 shows specifi-
} 
Finally, note that all of the terms on the right side of (5) are proportional to the source's exposure to the US labor market, $\xi_{s}$. For expositional clarity and to aid in interpreting the associated regressions, we divide the entire expression by $\xi_{s}$. We also plug in the controls just discussed and the observable US employment shock in (6), and replace the parameters $\alpha, w$, and $\gamma$ with reduced-form regression coefficients, $\beta, \Lambda$, and $\Pi$, yielding the following estimating equation,

$$
\frac{1}{\xi_{s}} \Delta y_{s}=\beta\left[\sum_{d \neq s} \varphi_{s d} \sum_{i} \frac{E m p_{i d}^{M}}{E m p_{d}^{M}} \frac{d E m p_{i d}}{E m p_{i d}}\right]+\phi_{e(s)}+\Lambda \Delta \mathbf{X}_{\mathbf{s}}+\Pi \sum_{d \neq s} \varphi_{s d} \Delta X_{d}+\varepsilon_{s}
$$

where $\varepsilon_{s}=\nu_{s} / \xi_{s}$. We have replaced the source population growth with $\Delta y_{s}$ to indicate a change in a generic source-level outcome. Note that the Mexican state fixed effects, $\phi_{e(s)}$, subsume the standard intercept term. This equation relates the exposure-normalized change in outcome in municipio $s$ to the change in US employment faced by migrants from that destination. ${ }^{22}$ Because dividing the dependent variable by $\xi_{s}$ may introduce heteroskedasticity, we use feasible GLS weighting to improve the efficiency of our estimates, following Wooldridge (2013) Section 8.4, and report standard errors clustered at the Mexican commuting-zone level. ${ }^{23}$ Mexican commuting zones are contiguous groups of economically integrated municipios. We assign municipios to Mexican commuting zones using the crosswalk constructed by David Atkin (Atkin 2016) and by making manual adjustments for municipios boundaries that changed over time, resulting in 1,829 separate commuting zones in Mexico.

Our coefficient of interest, $\beta$ in (8), compares the change in outcome between municipios in the same Mexican state whose migrants face larger vs. smaller US employment declines during the Great Recession. To interpret this relationship as causal, there must be no unobserved variables that influence municipio outcome growth that are also correlated with the size of the US employment declines faced by the municipio's migrants. This assumption is plausible in our context because the cations with subsets of controls for the remaining outcomes.

${ }^{22}$ Appendix A-3.1 shows that there is extensive variation in the municipio-level US employment shock for all values of exposure.

${ }^{23}$ In Appendix A-3.3, we present unweighted results along with Breusch-Pagan test statistics for heteroskedasticity. This additional analysis supports the conclusion that the weighted analysis is appropriate and improves efficiency. 
shocks and outcomes apply to different countries; unobserved developments in Mexican municipios are unlikely to be related to US labor demand shocks in the municipio's historical migrant destinations. Moreover, the model-derived estimating equation provides clear guidance on the classes of controls to include in the analysis. As shown in the following sections, our results are robust to omitting or including these controls and controls for pre-Recession outcome growth.

\section{Data and Measurement}

Throughout our analysis, we treat Mexican municipios as independent migrant source communities. $^{24}$ This is the finest level of geography identifiable across all of our various datasets, and, as shown in Figure 2, the US destination mix is often quite different even for migrants from geographically proximate municipios. We treat US Commuting Zones $(\mathrm{CZs})$ as potential migrant destinations because each $\mathrm{CZ}$ is designed to represent an integrated local labor market.

The US employment shock, the term in square brackets in (8), is calculated using information on the migration network and changes in US employment from before to after the Great Recession. As in Section 2.2, we measure the migration network term as $\varphi_{s d}=m_{s d} / \sum_{d^{\prime}} m_{s d^{\prime}}$, i.e. destination d's share of MCAS cards issued to migrants from source $s$ in 2006. Emp $p_{i d}$ is employment in industry $i$ and commuting zone $d$ in 2006 (prior to the Great Recession), and $d E m p_{i d}$ is its change from 2006 to 2010 (bracketing the Great Recession). We calculate these employment measures using the County Business Patterns and American Community Surveys as described in Section 2.1. ${ }^{25}$ $E m p_{i d}^{M} / E m p_{d}^{M}$ measures the share of Mexican-born workers living in $\mathrm{CZ} d$ who work in industry $i$ which we calculate using the 2006 American Community Survey. Combining this information as in (8) allows us to measure the US jobs lost per migrant from each source $s$.

The exposure term, $\xi_{s}$, reflects the share of those born in a given source municipio who live in the US. This stock of migrants at the source-destination level, $M_{s d}$, is not directly observable

\footnotetext{
${ }^{24}$ For a more detailed discussion of data sources and variable construction summarized in this section, see Appendix A-2

${ }^{25}$ We primarily use CBP data, but we fill in data for non-covered industries from the ACS. See footnote 13 for details.
} 
in any data source that we are aware of. We instead combine 2006 ACS estimates of the stock of Mexican-born migrants living in each US destination with migrant network information from MCAS to estimate $\xi_{s}$. Specifically, we apportion the 2006 Mexican-born population observed in each destination, $M_{d}$, to source municipios based the each source's share of identity cards issued to residents of that destination $\mathrm{CZ}$ in 2006 :

$$
M_{s d}=\left(\frac{m_{s d}}{\sum_{s^{\prime}} m_{s^{\prime} d}}\right) M_{d} \quad \forall d \neq s
$$

Finally, we calculate the Mexican-born population living in each source municipio, $M_{s s}$, using the 2005 Mexican Inter-Censal Count. The exposure for source $s$ is then the share of people from the source living in the US:

$$
\xi_{s}=\frac{\sum_{d \neq s} M_{s d}}{M_{s s}+\sum_{d \neq s} M_{s d}} .
$$

We examine the effects of US employment shocks on a variety of demographic and economic outcomes in Mexican municipios. We measure most outcomes using full-count tabulations from the 2005 Inter-Censal Count and 2000 and 2010 Mexican Censuses of Population. This survey timing allows us to measure changes in outcomes from 2005 to 2010, spanning the Great Recession, and to control for pre-existing changes in outcomes from 2000 to 2005. These outcomes include population growth, return migration, the population sex ratio, educational attainment among adults, household appliance ownership, and school attendance among children. For emigration and household remittance receipt, we measure the outcome in the 2010 Census and the pre-existing value in the 2000 Census because the 2005 Inter-Censal Count omits questions on these topics. Finally, we measure municipio aggregate labor earnings and aggregate hours in the 1999, 2004, and 2009 Mexican Economic Census. This data source allows us to measure changes in earnings, hours, earnings to population ratio, and earnings per hour from 2004 to 2009, spanning the Great Recession, and pre-existing changes from 1999 to $2004 .^{26}$

\footnotetext{
${ }^{26}$ The inclusion of these pre-Recession outcome controls directly addresses the possibility that pre-existing population growth differed across sources facing different shocks (Monras 2020). This approach also partly absorbs variation that might confound the analysis if markets adjust slowly to prior shocks (Jaeger et al. 2019). Because our migration network data begin in 2006, we are unable to calculate US shocks faced by migrants from different municipios
} 
In addition to pre-Recession outcome controls, we present specifications controlling for other municipio-level developments, including changes in the local homicide rate and changes in trade with the US. ${ }^{27}$ We control for local homicides to capture the effects of drug-related violence in Mexico during our study period. We use administrative data on homicides from the Mexican Statistical Office (INEGI) and measure the number of homicides during 2005-2010 divided by the 2005 population from the Inter-Censal Count. We control for the sharp reduction in trade between Mexico and the US during the Great Recession using a weighted average of industry-level changes in trade value from the period 2001-05 to the period 2006-10, weighted by the municipio's initial industry mix of employment in 2004. Because this trade control has a shift-share structure across tradable industries, we also control for the share of employment in nontradable sectors in 2004 to address the "incomplete shares problem" raised by Borusyak, Hull and Jaravel (2019). ${ }^{28}$

We also account for changes in US destinations $\left(X_{d}\right)$ that affect their attractiveness to potential migrants for reasons other than the employment shocks. These controls include indicators for new state-level anti-immigrant employment legislation and indicators for new 287(g) agreements that allow local officials to enforce federal immigration law. Both variables are based on the immigration policy database complied by Bohn and Santillano (2012). For each of these measures, we follow (8) and calculate a weighted average of changes in the policy indicators with weights based on the destination distribution of migrants from the relevant municipio.

Our analysis focuses on source municipios for which where we can accurately measure both the US employment shock and key dependent variables. We initially focus on municipio population growth and on the contributions of emigration and return migration specifically. Because these dependent variables are measured as shares of the initial population, they are highly sensitive to measurement error in small-population municipios. Further, the US employment shock requires accurate measures of each municipio's migrant-destination distribution. To address each of these during the period that preceded the Great Recession. Moreover isolating demand shocks is more challenging in a non-recessionary environment.

${ }^{27}$ Because these controls may themselves be affected by the US employment shocks, we show that our findings are robust to including or excluding them from the analysis.

${ }^{28}$ See Appendix A-2 for the details of the construction of these controls. 
concerns, we limit the sample to the 866 municipios that had at least 5,000 residents in the year 2005, had exposure $\xi_{s}>0.066$ (the 25th percentile), and whose citizens received at least 100 MCAS cards in 2006. The municipios in our analysis sample account for more than 56 percent of the working-age Mexican population in 2005, and their residents received nearly 765,000 out of the roughly 923,000 MCAS identity cards issued in 2006.

Descriptive statistics appear in Table 1. The difference between the 90th percentile and the 10th percentile US employment shock is 6.5 percentage points. We will use this difference to interpret the magnitudes of the estimated effects by comparing municipios facing relatively large and relatively small US employment declines. The average municipio in our sample had an exposure to the US labor market $\left(\xi_{s}\right)$ of approximately 25 percent, reflecting the fact that our sample uses municipios with relatively strong migrant ties to the US. Because we will divide each of the dependent variables by this exposure variable, interpreting the magnitude of the resulting coefficients requires a reference level of exposure, and we will use this average in our interpretation. Note that the descriptive statistics for the outcome variables listed in this table represent the values of the outcome variable prior to dividing by exposure.

Our identification strategy relies on within-Mexican-state variation in the network-weighted US employment shock faced by migrants and potential migrants from different source municipios. Figure 3 demonstrates the geographic variation in these employment shocks experienced by each Mexican source community, controlling for Mexican-state fixed effects. We show municipios facing larger US demand declines in darker blue and municipios connected to smaller declines in lighter blue. Municipios excluded from our analysis are shown in white. The clear differences in US employment shocks, even for geographically proximate municipios in the same state, provide the identifying variation driving the empirical results in the next section. 


\section{Results for Population Changes and Remittances}

Our empirical analysis begins by finding the effect of US employment shocks on the overall growth of a municipio's population, consistent with the comparative static modeled in Section 3. We then examine the contribution of both emigration and return migration to the total population response. Next, we use the same empirical specification to document additional effects on the demographic composition of the municipio population and the likelihood that households received remittance income. Together, these initial outcomes are the primary channels through which migrant networks transmitted US local economic shocks to Mexican sending communities. After finding substantial effects on these mechanisms, we examine in the next section how the loss of access to a strong US labor market affected Mexican labor market outcomes and household investment decisions.

\subsection{Effects on Population Size and Migration}

\subsubsection{Population and Migration Measures}

Municipio populations are directly observable every five years in the Census and in the InterCensal Count (Conteo). We measure working-age population growth as the proportional change in population ages 15-64. Both of these surveys also include questions about respondents' current location and their location of residence 5 years prior to the survey, allowing us to identity return migrants as those living in Mexico during the survey period and who lived in the US 5 years earlier. ${ }^{29}$ Given the timing of the surveys, we can identify return migrants who moved from the US to Mexico during three five-year periods: 1995-2000, 2000-2005, and 2005-2010. We then measure return migration's contribution to population growth as the number of working-age return migrants to a given municipio, divided by the community's population at the start of the period. Note that this measure is not a traditional return migration rate, as the denominator is the municipio population rather than the number of people born in the municipio who were living abroad.

Information on emigration is not available in the 2005 Conteo, so we have emigration measures

\footnotetext{
${ }^{29}$ The count of return migrants does not include any individuals who moved to the US and back within the five-year window.
} 
only from the 2000 and 2010 Censuses. These surveys ask households in Mexico whether a household member emigrated to the US during 1995-2000 or 2005-2010, respectively. Because this question is available only in the long-form survey, we have information for an approximately $10 \%$ sample of the Mexican population. Although this measure allows us to observe instances where one or more family members move to the US while some of the household remains in Mexico, it does not capture whole-household migration, because no one remains in Mexico to be surveyed. Our emigration measure is the number of working-age emigrants over a five-year interval divided by the working-age population at the start of the interval.

\subsubsection{Results for Population Changes}

Table 2 estimates Equation (8) using population growth and migration outcomes. Recall from Section 3 that we divide all dependent variables by the municipio's exposure to the US labor market, i.e. the share of people born in municipio $s$ who were living in the US in 2005. This adjustment accounts for the fact that population growth in sources with more people living in the US is more affected by any changes in the relative attractiveness of living at home or abroad. In columns (1)-(3), we provide results for population growth. The coefficient on the US employment shock is consistently negative and statistically significant, meaning that municipios connected to US destinations with larger job losses experienced larger increases in local population. Columns (2) and (3) include additional controls to account for possible omitted variable bias. In column (2), we add population growth over the prior five year period, which allows for the possibility that municipios facing more negative demand shocks were previously on systematically different trends in population growth. Column (3) adds controls of the type suggested by the model, including weighted averages of newly implemented destination-level immigration policies along with sourcecommunity trade shocks and homicide rates. Including these sets of controls reduces the size of the coefficient somewhat, but the coefficient of interest in column (3) is still statistically significantly distinguishable from zero $(\mathrm{p}<0.05)$.

Interpreting the magnitude of the coefficient requires three pieces of information: the coeffi- 
cient estimate, a difference in shock size, and a value for exposure to the US. From Table 1, the typical municipio in our sample had 25 percent of its population living in the US, and the 90-10 percentile difference in shock size was roughly 0.065. Therefore, the estimate in column (3) implies that when comparing two municipios with average exposure and a substantial difference in shock size, the more affected municipio experienced 2.3 percentage points faster population growth $((-1.422)(.25)(-.065)=0.023)$.

\subsubsection{Results for Return Migration and Emigration}

A decline in US labor demand should lead to both an increase in return migration to Mexico and a decline in emigration to the US. Figure 4 confirms this intuition in the aggregate. Following substantial net migration to the US in the 1990s and early 2000s, during 2005-2010 emigration to the US fell by 32 percent and return migration to Mexico quadrupled. ${ }^{30}$ These patterns are consistent with the interpretation that a decline in labor market opportunities led to a slowdown in net migration to the US. The remainder of Table 2 leverages spatial variation in demand conditions to further examine this hypothesis. ${ }^{31}$

Because our return migration and emigration measures are scaled by the initial municipio population, they can be interpreted as the contribution of each migration flow to local population growth. ${ }^{32}$ The coefficients on the US shock have the expected sign for both outcomes: municipios exposed to larger US job losses saw substantially larger return migration (columns (4)-(6)) and smaller emigration (columns (7)-(9)) during the 2005-2010 time period. The coefficients on the US employment shock are relatively stable across specifications, and the magnitudes are similar (although oppositely signed) for both the return migration and emigration outcomes. This similarity

\footnotetext{
${ }^{30}$ The substantial increase in the early 2000s has been documented elsewhere, including in Card and Lewis (2005), with explanations including the poor economic performance of Mexico after the ratification of the North American Free Trade Agreement (NAFTA) in 1990 and the Mexican Peso crisis of 1991 (Chiquiar and Salcedo 2013, Monras 2015, Fajardo et al. 2017). Other analysis of higher-frequency data also shows a substantial slowdown over this time period, with annual net arrivals of fewer than 200,000 migrants (Passel, Cohn and Gonzalez-Barrera 2012).

${ }^{31}$ The nationwide emigration numbers shown in this figure are from CONAPO, which does not allow for the calculation of municipio-specific migration rates.

${ }^{32}$ Note that internal migration, aging in and out of the working-age sample, and mortality may also affect local population growth.
} 
suggests that both return migration due to lost jobs and potential migrants choosing not to leave for the US while demand was weak were important drivers of population adjustment in Mexican sources. Note that because the return migration and emigration measures are based on different samples covering different portions of the population, there is scope for substantial differences in the population growth implied by observed migration flows and the population growth measured most accurately based on Census head counts.

\subsection{Effects on Population Composition and Remittance Receipt}

Along with effects on the size of local populations in Mexico, US employment declines may have altered the composition of the population, particularly because the characteristics of return migrants differed on average from those of the overall Mexican population. Table 3 and Figure 5 use 2010 Mexican Census data to compare return migrants to non-migrants, demonstrating that return migrants are much more likely to be male (69 percent vs. 49 percent) and are more likely to have primary-school education rather than higher or lower levels. They are also more likely to be married, and they have higher levels of labor force attachment, each of which is likely related to the fact that return migrants disproportionately fall in the 25-45 age range. Although return migration represents only a portion of the overall population adjustment, we expect residents who chose not to emigrate in response to the decline in labor demand to share similar characteristics. The changing migration flows documented in the prior subsection should therefore lead to changes in the composition of the local labor force.

Column (1) of Table 4 examines changes in the female-to-male sex ratio for working-age (16-54) individuals. The positive coefficient estimate for the US employment shock implies that municipios facing larger US employment declines had larger declines in the sex ratio, consistent with return migrants being disproportionately male. ${ }^{33}$ The coefficient's magnitude implies that the sex ratio in a municipio facing the 90th percentile shock fell by 0.008 more than in a municipio at the 10th percentile, which is 20 percent of a standard deviation in the change in sex ratio over this time

\footnotetext{
${ }^{33}$ For concision, Table 4 only shows specifications with the full set of controls. Results for alternative specifications appear in Appendix A-3
} 
period. Based on the comparisons shown in Table 3, it was possible that the US employment shocks also changed the distribution of educational attainment in affected municipios. The results in columns (2)-(5) of Table 4, however, show no statistically significant relationship between the shock and the share of population with any particular level of education. These results imply only a limited scope for the US shocks to affect wages in Mexican municipios because they alter only the aggregate amount of labor in a given municipio and not the relative supplies of different skill levels. Consistent with this interpretation, we find no substantial wage effects in the next section.

Declines in US labor demand not only reduce the relative value of locating in the US, but they also decrease migrants' ability to send money back to Mexico. Column (6) of Table 4 examines the relationship between US shocks and the share of households receiving remittances from abroad in 2010. Because households are not asked about remittance receipt in the Conteo, we control instead for the year-2000 share of households receiving remittances to account for pre-existing differences in remittance behavior across municipios. ${ }^{34}$ The coefficient on the US labor demand shock is positive and strongly statistically significant, implying that households in the municipios facing larger declines in US labor demand were less likely to receive remittances, even after controlling for the baseline remittance share in 2000. The point estimate of 0.6 in column (6) implies that, for municipios with average exposure to the US, a strongly affected community saw a roughly 1 percentage point larger decline in the share of households receiving remittances compared to a less affected community $((0.602)(0.25)(-0.065)=0.0098)$. This is a substantial decrease compared to the mean of 4 percent.

Together, the results in this section show that US local labor demand shocks during the Great Recession affected Mexican sending communities through a variety of channels. Because many US destination markets became much less attractive during this time period, former migrants returned to Mexico, and potential migrants chose not to move to the US. These shifts led to increased population growth in municipios facing larger US labor demand declines and changes in the gender mix of working-age populations. The decline in US employment opportunities also reduced the share

\footnotetext{
${ }^{34}$ This specification is therefore similar to the return migration specification that asks whether more affected municipios received more return migrants, controlling for the amount of return migration in the prior five years.
} 
of Mexican households receiving remittances from abroad. In the following section, we examine how these changes in the size and composition of the local labor force and the reduction in household budgets due to declining remittances affected employment, earnings, and household investment behavior in migrant source communities.

\section{Labor Market and Investment Outcomes}

\subsection{Labor Market Outcomes}

To credibly measure labor market outcomes at the detailed municipio level, we use full-count tabulations from the 2004 and 2009 Mexican Economic Census, which cover all formal economic activity in Mexico outside agriculture, livestock, forestry and a few service industries. ${ }^{35}$ These data allow us to measure municipio-level employment (separately by gender), aggregate yearly earnings, and aggregate yearly hours worked in covered sectors.

Given the declines in employment opportunities in the US, we expect households to compensate by increasing labor supply in Mexico. We first consider changes in the share of the local population that is employed. Increases in this metric may reflect the higher labor force attachment of return migrants compared to the broader population (Table 3) or household members newly entering the labor force. Column (1) of Table 5 examines the change in the municipio employment-topopulation ratio from 2004 to 2009, using employment from the Economic Census and population from the 2005 Inter-Censal Count or 2010 Census, respectively. All of the specifications in this table include the full set of controls. The negative coefficient estimates for the US employment shock imply that sources facing larger US employment declines exhibited larger increases in the employment to population ratio. Panels $\mathrm{B}$ and $\mathrm{C}$ make clear that the overall effect in Panel A is driven almost entirely by women. ${ }^{36}$ The coefficient of -0.85 in Panel B implies that a strongly

\footnotetext{
${ }^{35}$ Service sectors that are not covered by the Economic Census include mass transit, taxis, farmers' insurance funds, political organizations, and domestic employees (INEGI 2009).

${ }^{36}$ Although this analysis is not limited to married women, this result is similar to the "added worker effect" in which married women enter the labor force after their husbands lose employment. See Stephens (2002) for a thorough review of this literature. In Section 6.1.1, we present descriptive evidence suggesting that differences in labor supply
} 
affected municipio with average exposure to the US experienced a 1.4 percentage point larger increase in employment to population ratio among women compared to a similar municipio that was less affected $((-0.847)(0.25)(-0.065)=0.014)$. Employment rates for men, however, did not change differentially based on the municipio's US labor demand shock, in spite of the fact that the vast majority of return migrants were men. This pattern of results suggests that return migrants and non-emigrants did not substantially crowd out employment in source communities. The loss of remittance income from higher-paying US jobs, however, led more women to enter the workforce.

Columns (2)-(4) demonstrate that local labor markets were able to accommodate substantial increases in the supply of hours worked without substantially reducing wages. The second and third columns show that both total municipio-level hours worked and total earnings increased in the most affected source communities. Note that both of these aggregate outcomes are affected directly by the increase in population shown in the previous section. Comparing two municipios at the 90th and 10th percentile of the shock distribution, the more affected municipio experienced a 7 percentage point larger increase in local hours and a 10 percentage point larger gain in total earnings. If the increase in labor supply had put downward pressure on wages, total earnings would have risen by a smaller percentage than hours did. Instead, as confirmed in the final column, which uses earnings per hour as the dependent variable, the negative coefficient on the US shock implies a small increase in the wage rate for municipios facing more negative US shocks, although this estimated effect is not statistically significant. Note, however, that we are unable to disaggregate earnings or hours by gender or migration status, so we cannot directly address whether particular groups faced downward wage pressure.

Overall, these results are consistent with the broader international migration literature, which typically finds modest effects of migration-related population growth on local equilibrium wages (National Academies of Sciences, Engineering, and Medicine 2017). Recall that Table 4 found no significant effects on the educational composition of municipios' working-age populations. Because there was no change in the skill mix in affected municipios, the lack of a wage effect could be are driven primarily by women in households with US migrants. 
explained by modest capital adjustments over a five year period (Borjas 2013). Finally, one might be concerned that municipios in the same Mexican commuting zone might might be part of an integrated labor market in equilibrium. In Appendix A-3.4, we provide very similar results when aggregating the unit of analysis to the Mexican commuting zone level, showing that the choice of Mexican market aggregation does not substantially affect our findings.

\subsubsection{Supporting Evidence from Cross-Sectional Analysis}

Our interpretation of the results in Table 5 presumes that the observed labor supply responses occurred in Mexican households with US migrants, i.e. among those who were directly affected by a loss of US employment opportunities during the Great Recession. An ideal analysis would assess this interpretation using panel data to observe household-level changes in labor supply in response to return migration or a loss of remittances. Since no such panel data are available, as an alternative we examine whether employment probabilities for members of households with US migrants are more strongly related to the US shocks faced by potential migrants from their communities compared to households without US migrants.

We implement this supporting analysis using data from the 2010 Census. We define households that were exposed to the US labor market as those with either i) a return migrant who had lived in the US in 2005 but returned to Mexico by 2010 or ii) a former household member who left for the US after 2005. Individuals living in households meeting this definition are identified by the indicator function $\mathbb{1}\left(\operatorname{exposed}_{j}\right)$ and referred to as "members of exposed households." We then use the following individual-level regression to ask whether the cross-sectional relationship between non-migrants' labor supply and US shocks is driven primarily by these individuals with direct ties 
to the US labor market.

$$
\begin{aligned}
\mathbb{1}\left(\text { employed }_{j}\right)= & \beta_{1} \mathbb{1}\left(\operatorname{exposed}_{j}\right) \cdot\left[\sum_{d \neq s} \varphi_{s d} \sum_{i} \frac{E m p_{i d}^{M}}{E m p_{d}^{M}} \frac{d E m p_{i d}}{E m p_{i d}}\right] \\
& +\beta_{2} \mathbb{1}\left(\operatorname{exposed}_{j}\right)+\beta_{3}\left[\sum_{d \neq s} \varphi_{s d} \sum_{i} \frac{E m p_{i d}^{M}}{E m p_{d}^{M}} \frac{d E m p_{i d}}{E m p_{i d}}\right] \\
& +\phi_{e(s)}+\Lambda \Delta X_{s}+\Pi \sum_{d \neq s} \varphi_{s d} \Delta X_{d}+\epsilon_{j}
\end{aligned}
$$

If reductions in US employment faced by a person's municipio (the terms in square brackets) increase employment probabilities more for members of migrant households, the estimate of $\beta_{1}$ will be negative.

The results in Table 6 confirm this expected pattern. Columns (1) and (2) estimate the specification in (11) (column (1) omits the controls), and column (3) estimates a more general specification subsuming all municipio-level terms into municipio fixed effects, including the non-interacted US employment shock, controls, and Mexican state fixed effects. Panel A shows the results for all individuals. The interaction term's coefficient, $\hat{\beta}_{1}$, is negative and significant in columns $(1)$ and (2) with state fixed effects, and negative but statistically insignificant in column (3) with municipio fixed effects. Figure 6 shows a binscatter plot visualizing the variation identifying $\beta_{1}$ in column (1). The gray circles plot the employment share of working-age population for those in unexposed households (without US migrants) and the black diamonds show employment shares for those in exposed households. For unexposed households, there is no relationship between the employment probability and the US employment shock; this is expected because unexposed households by construction were not directly affected by US employment declines. In contrast, there is a strong negative relationship for members of exposed households. Column (2) in Table 6 confirms that this pattern holds when including the full battery of controls as well. ${ }^{37}$ Moreover, just as in Table 5, these employment effects among exposed households are driven almost entirely by women, for whom we find a significant negative effect even in the very demanding specification in column (3)

\footnotetext{
${ }^{37}$ Results are qualitatively similar to those in columns (1) and (2) of Table 6, though a bit less precise, when controlling for state $\times$ exposure status fixed effects.
} 
of Panel B, with municipio fixed effects. These cross-sectional results strongly support the interpretation that when migrants' households lost income due to negative employment shocks during the US Great Recession, other household members, particularly women, sought to compensate by entering the labor force.

\subsection{Investment Results}

If households are unable to fully adapt to a loss of US labor market income, they may adjust on other consumption and investment margins as well. Table 7 shows the effects of US labor demand shocks on two sets of investment behaviors: ownership of household durables and human capital investment via school attendance. Each column provides the results of a separate regression, returning to the specification in (8) with alternative dependent variables. The first four columns consider the change in the share of households owning the relevant household durable from 2005 to 2010, including personal computers, washing machines, refrigerators, and televisions. The coefficient on the US employment shock for televisions is positive and statistically significant, implying that households in more negatively affected municipios slowed down their purchases of televisions.

The final three columns use municipio-level school attendance rates among different age groups primary (age 6-12), early secondary (13-15), and late secondary (16-18) - as the dependent variables. The coefficients on the US employment shock are uniformly positive, meaning that declining US labor demand was associated with decreases in school attendance at all three levels. The coefficient is precisely measured only for the elementary school age outcome, however, where it implies a 0.4 percentage point larger larger decline in school enrollment for a municipio with average exposure connected to a very negative shock compared to one with similar exposure but a mild shock. Together, these results imply that the loss of access to a strong US labor market slowed investment in affected communities. These results are consistent with Caballero's (2020) findings in which school enrollment decreased in municipios with stronger migration ties to US destinations that adopted deportation policies. More generally, these findings are important because education early in life strongly influences future labor market outcomes. These differences in schooling attendance 
across municipios could lead to persistent inequalities among children at pivotal schooling ages during the Great Recession.

\section{Conclusion}

This paper documents the role of geographic migrant networks in transmitting the effects of the US Great Recession across the border to migrant-connected Mexican locations. The empirical analysis relies on variation in the magnitude of labor demand declines across US commuting zones and variation in the mix of US destination locations chosen by migrants from different Mexican municipios. We derive our empirical approach from a simple location choice model, showing how to combine these sources of variation, and we use administrative data from the Matrícula Consular de Alta Seguridad (MCAS) ID card program to observe migrant connections between municipios and US commuting zones. We compare changes in outcomes between municipios in the same Mexican state that faced larger vs. smaller declines in US employment and show that the results are robust to controlling for pre-existing differences in outcomes across municipios and other changes in the attractiveness of source and destination locations.

The results reveal that in municipios whose migrants faced larger US labor demand declines, the working-age population grew faster, return migration increased more, and emigration decreased more than in municipios facing smaller shocks. Household remittance receipt fell by more in these source locations as did the female-to-male sex ratio, since return migrants were disproportionately male. These changes in the size and composition of the local labor force, along with the reductions in household budgets due to lost remittance income, linked Mexican local labor market outcomes to US local labor demand shocks. Specifically, the employment-to-population ratio increased by more in harder hit regions, with the increase happening almost entirely among women. This change in female labor supply likely reflects households compensating for lost US earnings among migrants. We also find that households in locations facing more negative US shocks were less likely to purchase televisions and that school enrollment for children age 6-12 in those locations grew less than in other 
locations.

These findings demonstrate the substantial influence of the US labor market on Mexican demographic and economic outcomes, likely with long-lasting consequences. While this paper studies changes in US labor demand driven by the Great Recession, one can expect to find similar effects if a large portion of Mexican migrants lost access to the US labor market due to changes in immigration and enforcement policies. For example, a well enforced universal E-Verify program would largely cut off labor market access for unauthorized immigrants, including approximately 43 percent of Mexican-born residents of the US in 2019 (Gonzalez-Barrera and Krogstad 2019).

Along with these policy implications, our findings inform the broader literature on the effects of immigration on local labor markets. Specifically, we find that aggregate outflows from sending locations are strongly responsive to labor demand conditions in the subset of US destinations where previous migrants from that source had historically settled. This finding conflicts with a key assumption behind the most commonly used instrument to correct for the endogeneity of immigrant inflows, suggesting that alternative approaches may be needed. Finally, these findings reinforce the conclusion that US-Mexico migration operates through a series of tight connections between specific sources and destinations. Thus, we expect that any local shocks on one side of the border are likely to affect outcomes in migrant-connected localities on the other side. 


\section{References}

Albert, Christoph and Joan Monras, "Immigration and Spatial Equilibrium: the Role of Expenditures in the Country of Origin," working paper, 2019.

Allen, Treb, Cauê de Castro Dobbin, and Melanie Morten, "Border Walls," NBER Working Paper, 2019, (25267).

Altonji, Joseph G. and David Card, The Effects of Immigration on the Labor Market Outcomes of Less-skilled Natives, University of Chicago Press, January

Antman, Francisca M, "The intergenerational effects of paternal migration on schooling and work: What can we learn from children's time allocations?," Journal of Development Economics, 2011, $96(2), 200-208$.

_ , "The impact of migration on family left behind," International handbook on the economics of migration, 2013, (p 293).

Atkin, David, "Endogenous Skill Acquisition and Export Manufacturing in Mexico," American Economic Review, August 2016, 106 (8), 2046-85.

Bartel, Ann P, "Where do the new US immigrants live?," Journal of Labor Economics, 1989, 7 (4), 371-391.

Bohn, Sarah and Robert Santillano, "Do local immigration laws impact employment and wages? Evidence from the 287 (g) program," Public Policy Institute of California, 2012.

, Magnus Lofstrom, and Steven Raphael, "Did the 2007 Legal Arizona Workers Act reduce the state's unauthorized immigrant population?," Review of Economics and Statistics, 2014, $96(2), 258-269$.

Borjas, George J, "Does immigration Grease the Wheels of the Labor Market?," Brookings papers on economic activity, 2001, 2001 (1), 69-119.

_ _ "The analytics of the wage effect of immigration," IZA Journal of Migration, 2013, 2 (1), $1-25$. 
Borusyak, Kirill, Peter Hull, and Xavier Jaravel, "Quasi-experimental shift-share research designs," Mimeo, 2019.

Brum, Matias, "Italian Migration to the United States: The Role of Pioneers' Locations," unpublished, 2019.

Caballero, Maria E., Brian C. Cadena, and Brian K. Kovak, "Measuring Geographic Migration Patterns Using Matrículas Consulares," Demography, 2018, 55 (3), 1119-1145.

Caballero, María Esther, "The Effects of Immigration Enforcement on Educational Investments in Migrants' Source Regions," Working Paper, 2020.

Cadena, Brian C, "Native Competition and Low-Skilled Immigrant Inflows," Journal of Human Resources, 2013, 48 (4), 910-944.

Cadena, Brian C. and Brian K. Kovak, "Immigrants Equilibrate Local Labor Markets: Evidence from the Great Recession," American Economic Journal: Applied Economics, 2016, 8 (1), 257-290.

Card, David and Ethan Lewis, "The Diffusion of Mexican Immigrants During the 1990s: Explanations and Impacts," Technical Report w11552, National Bureau of Economic Research, Cambridge, MA August 2005.

Chiquiar, Daniel and Alejandrina Salcedo, "Mexican Migration to the United States: Underlying Economic Factors and Possible Scenarios for Future Flows," Banco de México Working Paper, 2013.

Chiswick, Barry and Timothy J Hatton, "International Migration and the Integration of Labor Markets," in "Globalization in historical perspective," University of Chicago Press, 2003, pp. 65-120.

Clemens, Michael, "The Effect of Occupational Visas on Native Employment: Evidence from Labor Supply to Farm Jobs in the Great Recession," IZA Discussion Paper Series, 2017, (10492). 
Conover, Emily, Melanie Khamis, and Sarah Pearlman, "Gender Imbalances and Labor Market Outcomes: Evidence from Large-Scale Mexican Migration," IZA Journal of Development and Migration, 2021, 12 (1).

Cortes, Patricia, "The feminization of international migration and its effects on the children left behind: Evidence from the Philippines," World Development, 2015, 65, 62-78.

Daly, Mary C, Bart Hobijn, and Theodore S Wiles, "Dissecting Aggregate Real Wage Fluctuations: Individual Wage Growth and the Composition Effect," FRB-SF Working Paper, May 2012, (2011-23).

Dinkelman, Taryn and Martine Mariotti, "The long-run effects of labor migration on human capital formation in communities of origin," American Economic Journal: Applied Economics, 2016, 8 (4), 1-35.

, Grace Kumchulesi, and Martine Mariotti, "Labor Migration, Capital Accumulation, and the Structure of Rural Labor Markets," Technical Report, Working Paper 2017.

Dorn, David, "Essays on Inequality, Spatial Interaction, and the Demand for Skills," PhD diss. 3613, University of St. Gallen., 2009.

Edin, Per-Anders, Peter Fredriksson, and Olof Åslund, "Ethnic enclaves and the economic success of immigrants - Evidence from a natural experiment," The quarterly journal of economics, 2003, 118 (1), 329-357.

Fajardo, Gustavo, Emilio Gutierrez, and Horacio Larreguy, "Taking One for the Team: Shocks at Destination and Households' Supply of Migrants," 2017.

Garip, Filiz and Asad L Asad, "Network effects in Mexico-US migration: disentangling the underlying social mechanisms," American Behavioral Scientist, 2016, 60 (10), 1168-1193.

Gonzalez-Barrera, Ana and Jens Manuel Krogstad, "What we know about illegal immigration from Mexico," June 2019. 
Hanson, Gordon $\mathbf{H}$ and Antonio Spilimbergo, "Illegal immigration, Border Enforcement, and Relative Wages: Evidence from Apprehensions at the US-Mexico Border," American Economic Review, 1999, 89 (5), 1337-1357.

INEGI, "Metodología de los Censos Econónomicos 2009," Technical Report, Instituto Nacional de Estadística y Geografía, México 2009.

Jaeger, David A., Joakim Ruist, and Jan Stuhler, "Shift-Share Instruments and Dynamic Adjustments: The Case of Immigration," unpublished, 2019.

Jr., Melvin Stephens, "Worker Displacement and the Added Worker Effect," Journal of Labor Economics, 2002, 20 (3), 504-537.

King, Ledyard, "Republican plan would raise minimum wage to $\$ 10$ but only if businesses are required to ensure worker legality," USA Today, February 232021.

Kosack, Edward, "Guest Worker Programs and Human Capital Investment: The Bracero Program in Mexico, 1942-1964," Journal of Human Resources, forthcoming.

Llull, Joan, "The effect of immigration on wages: exploiting exogenous variation at the national level," Journal of Human Resources, 2018, 53 (3), 608-662.

Massey, Douglas S and Kristin E Espinosa, "What's driving Mexico-US migration? A theoretical, empirical, and policy analysis," American journal of sociology, 1997, 102 (4), 939-999.

Massey, Douglas S., Jacob S. Rugh, and Karen A. Pren, "The Geography of Undocumented Mexican Migration," Mexican Studies/Estudios Mexicanos, February 2010, 26 (1), 129-152.

McKenzie, David and Hillel Rapoport, "Network effects and the dynamics of migration and inequality: theory and evidence from Mexico," Journal of development Economics, 2007, 84 (1), $1-24$.

Mishra, Prachi, "Emigration and Wages in Source Countries: A Survey of the Empirical Literature," in "International Handbook on Migration and Economic Development," Edward Elgar Publishing, 2014. 
Monras, Joan, "Immigration and Wage Dynamics: Evidence from the Mexican Peso Crisis," 2015, p. 54 .

_ _ "Economic Shocks and Internal Migration," unpublished, 2020.

Munshi, Kaivan, "Networks in the Modern Economy: Mexican Migrants in the U.S. Labor Market," The Quarterly Journal of Economics, 2003, 118 (2), 549-599.

National Academies of Sciences, Engineering, and Medicine, The Economic and Fiscal Consequences of Immigration, Washington, DC: The National Academies Press, 2017.

Passel, Jeffrey, D’Vera Cohn, and Ana Gonzalez-Barrera, "Net Migration from Mexico Falls to Zero and Perhaps Less," 2012, p. 47.

Pierce, Justin R. and Peter K. Schott, "A Concordance Between U.S. Harmonized System Codes and SIC/NAICS Product Classes and Industries," Journal of Economic and Social Measurement, 2012, 37 (1-2), 61-96.

Rothstein, Jesse, "The Labor Market Four Years into the Crisis: Assessing Structural Explanations," Industrial and Labor Relations Review, July 2012, 65 (3), 467-500.

Ruggles, Steven, Sarah Flood, Ronald Goeken, Josiah Grover, Erin Meyer, Jose Pacas, and Matthew Sobek, "Integrated Public Use Microdata Series: Version 8.0," 2017. Machinereadable database. Minneapolis: University of Minnesota.

Schnabl, Peter, "Migration and Development in Mexican Communities: Evidence from US Labor Demand Shocks," 2007, p. 51.

Secretaría de Relaciones Exteriores, "Do you know how many Mexicans live abroad?," December 2015 .

Theoharides, Caroline, "Manila to Malaysia, Quezon to Qatar: International Migration and Its Effects on Origin-Country Human Capital," Journal of Human Resources, 2018, 53 (4), $1022-1049$. 
Tian, Yuan, María Esther Caballero, and Brian K. Kovak, "Social Learning along International Migrant Networks," unpublished, 2020.

Winters, Paul, Alain de Janvry, and Elisabeth Sadoulet, "Family and Community Networks in Mexico-U.S. Migration," The Journal of Human Resources, 2001, 36 (1), 159.

Wooldridge, Jeffrey M, Introductory econometrics: A modern approach, 5th ed.Mason, OH: South-Western., 2013.

Yang, Dean, "International migration, remittances and household investment: Evidence from Philippine migrants' exchange rate shocks," The Economic Journal, 2008, 118 (528), 591-630. 
Figure 1: Change in U.S. Employment across CZs

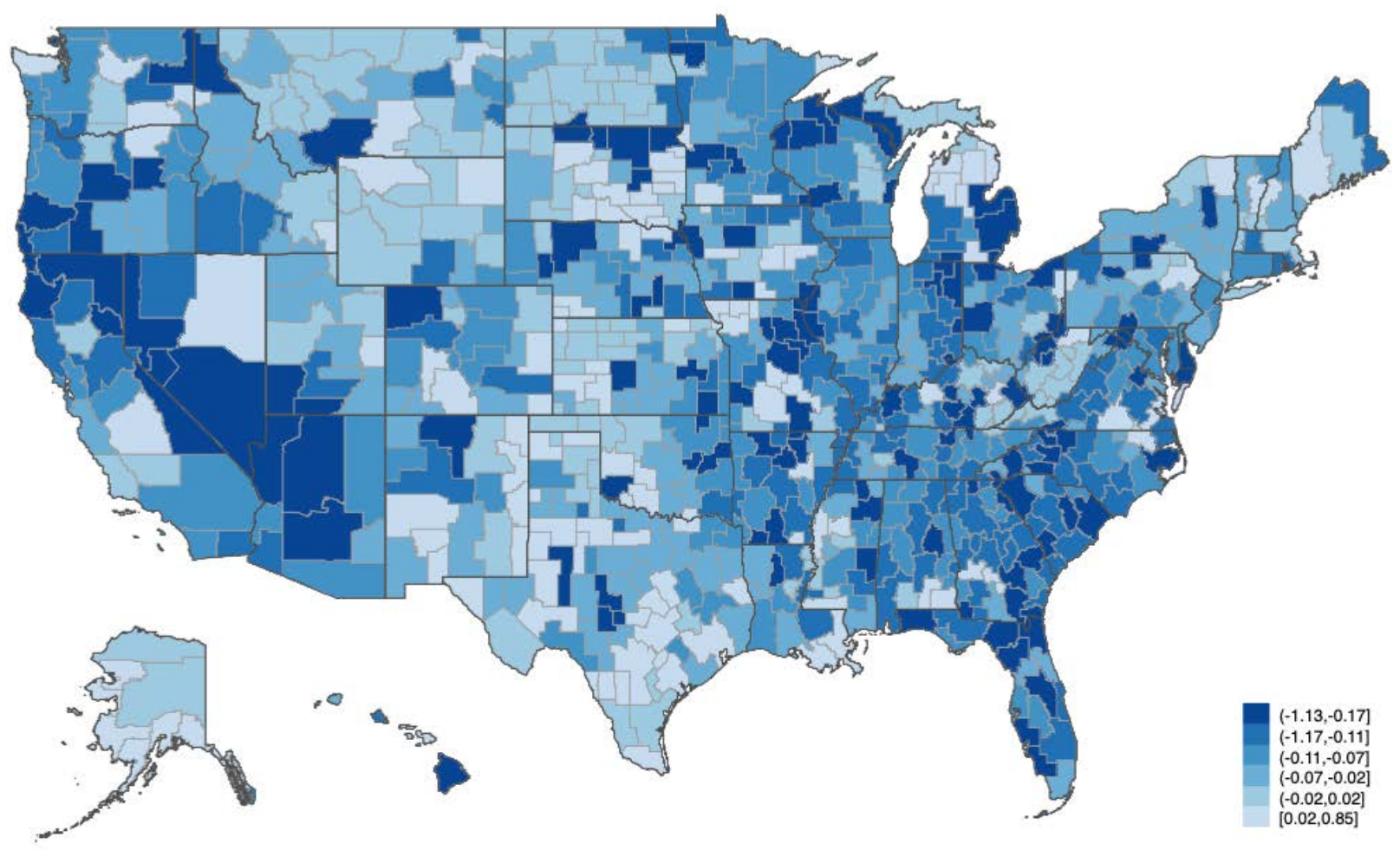

This map shows proportional changes in employment between 2006 and 2010 (bracketing the Great Recession) for each US commuting zone (CZ), with darker colors indicating larger declines in labor demand. Our measure accounts for Mexican-born workers' industry distribution of employment in each commuting zone (see main text). We use data from the County Business Patterns (CBP) supplemented with data from the American Community Survey (ACS) to fill in employment in a few industries that are not covered by the CBP. This variation in labor demand declines across US destinations leads to variation in network-connected labor demand across Mexican sources with different destination distributions (as shown in Figure 2). 


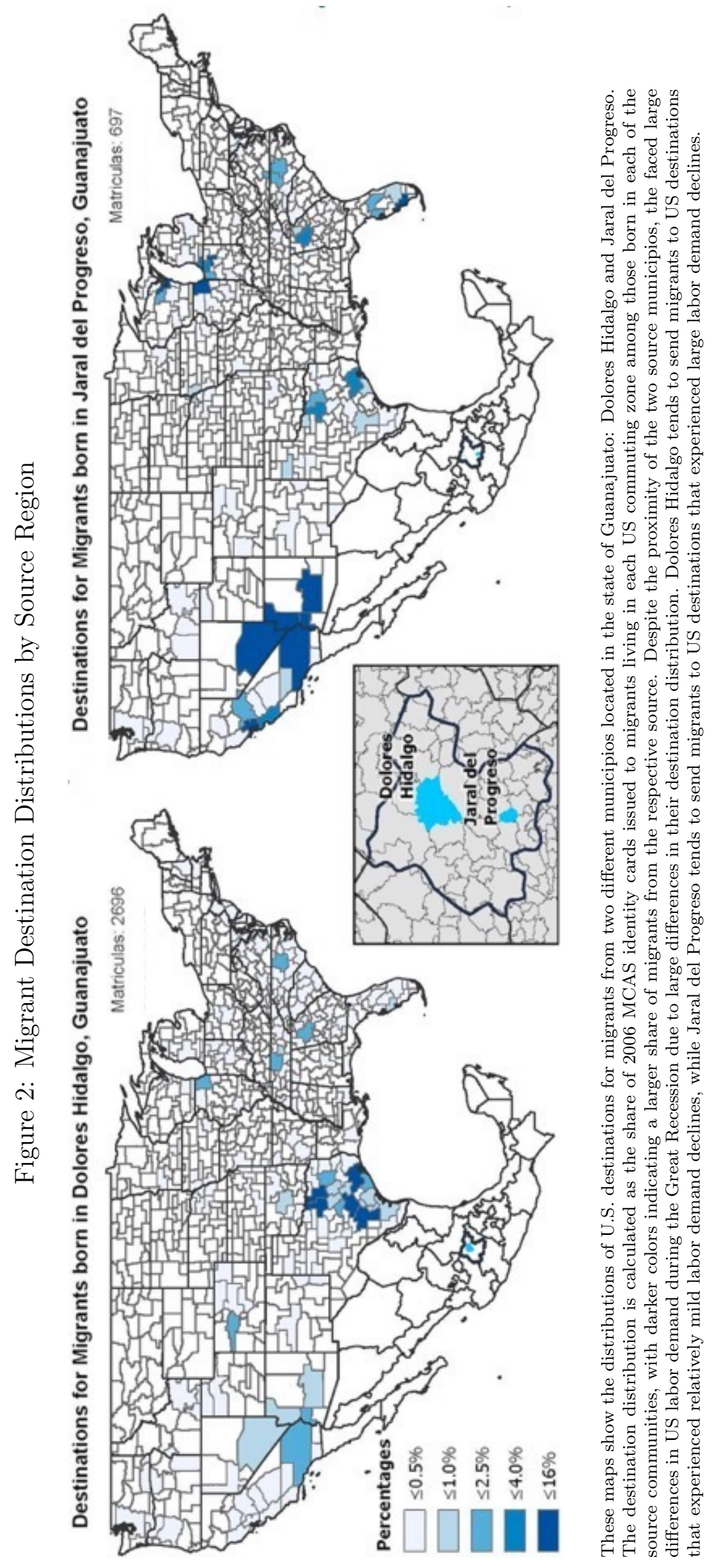


Figure 3: US Employment Shock Measure, Controlling for Mexican-State Fixed Effects

1

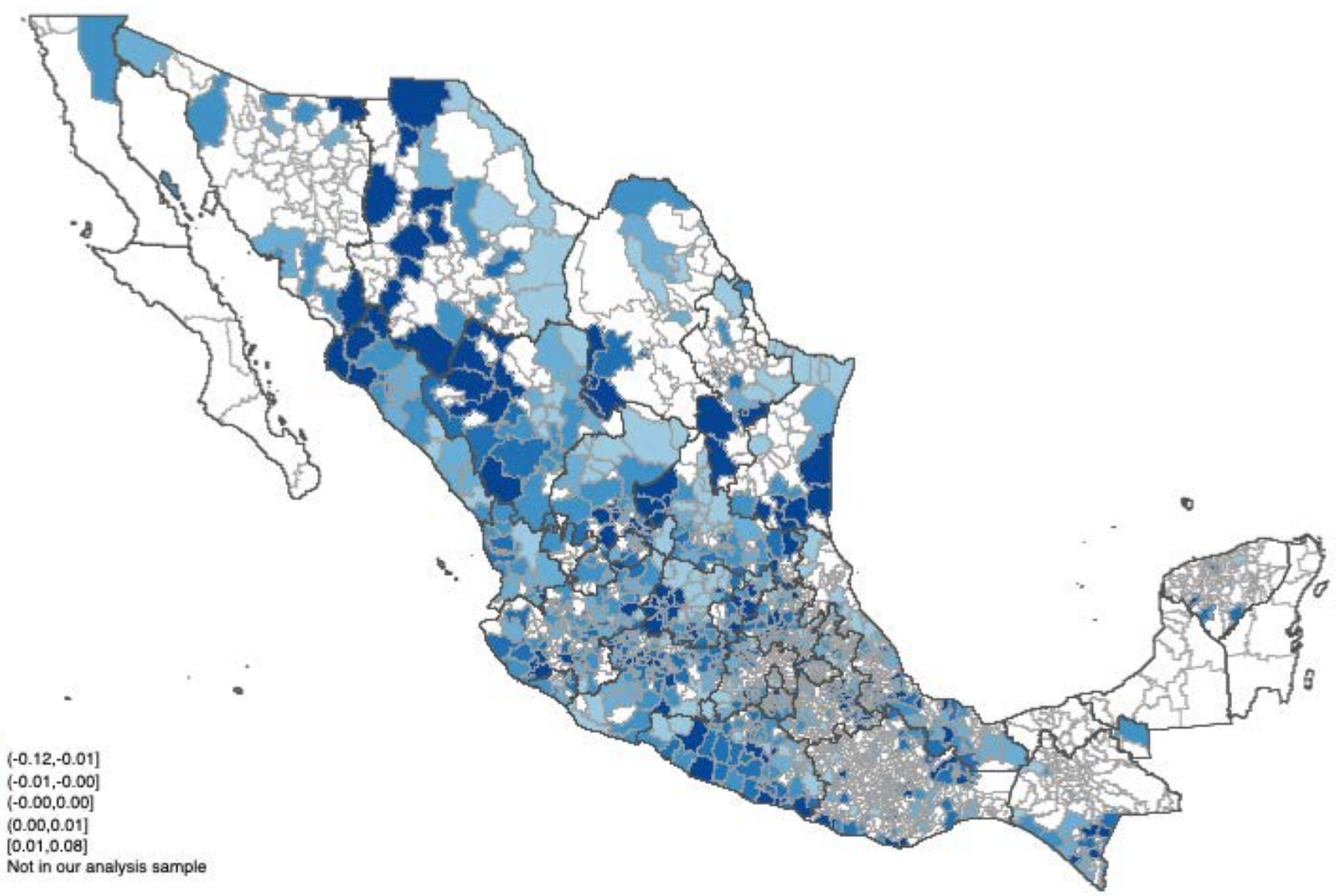

This map shows the distribution of network-connected changes in US labor demand (as defined in the main text) over the time period of the Great Recession for each Mexican municipio, controlling for Mexican-state fixed effects. Our sample omits municipios (shown in white) with less than 5,000 residents in 2005, with initial exposure less than 0.066, or with fewer than 100 matriculas issued in 2006. This sample restriction maintains $56 \%$ of the year-2005 working age Mexican population. The 90-10 percentile gap in the network-connected change in US labor demand distribution is 0.065. Because our analyses include Mexican-state fixed effects as control variables, the variation displayed in this map is the key identifying variation in our analysis. 
Figure 4: Five-Year Migration Flows Between Mexico and the U.S.

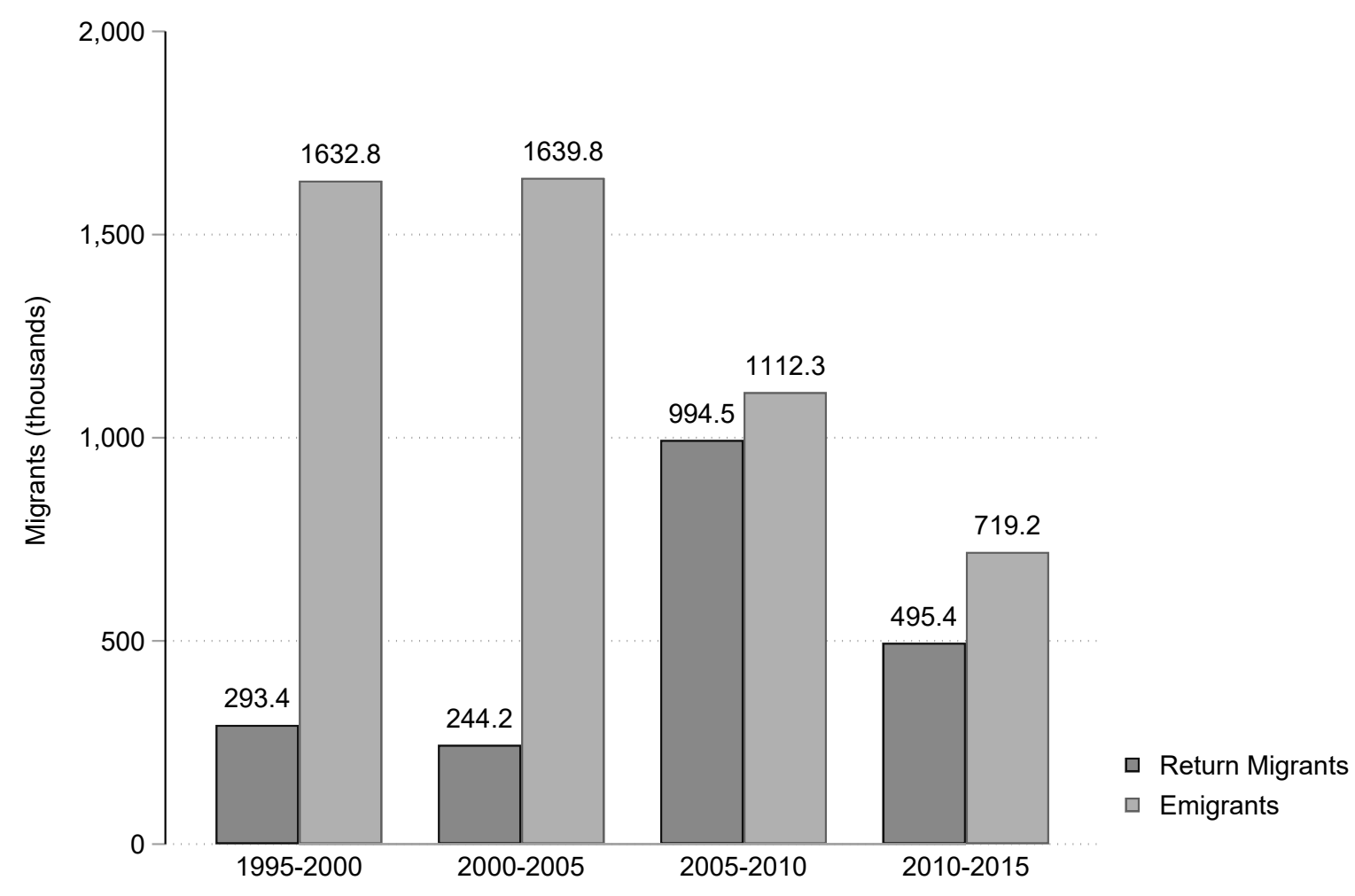

Authors' calculations using data from INEGI and CONAPO. Return migration is calculated using the 2000 and 2010 Mexican Census, the 2005 Inter-Censal Count (Conteo) and the 2015 Inter-Censal Survey (Encuesta Intercensal). The return migration measure counts the number of people in Mexico reporting living abroad five years prior to the survey. Emigrants are calculated using data from the 2000 and 2010 Mexican Census and data from CONAPO for 2005 and 2015. The measure counts the number of emigrants leaving surveyed households within the five year period preceding the survey. Note the large increase in return migration to Mexico in 2005-10, during the US Great Recession. 
Figure 5: 2005-2010 Return Migrants' Age Distribution

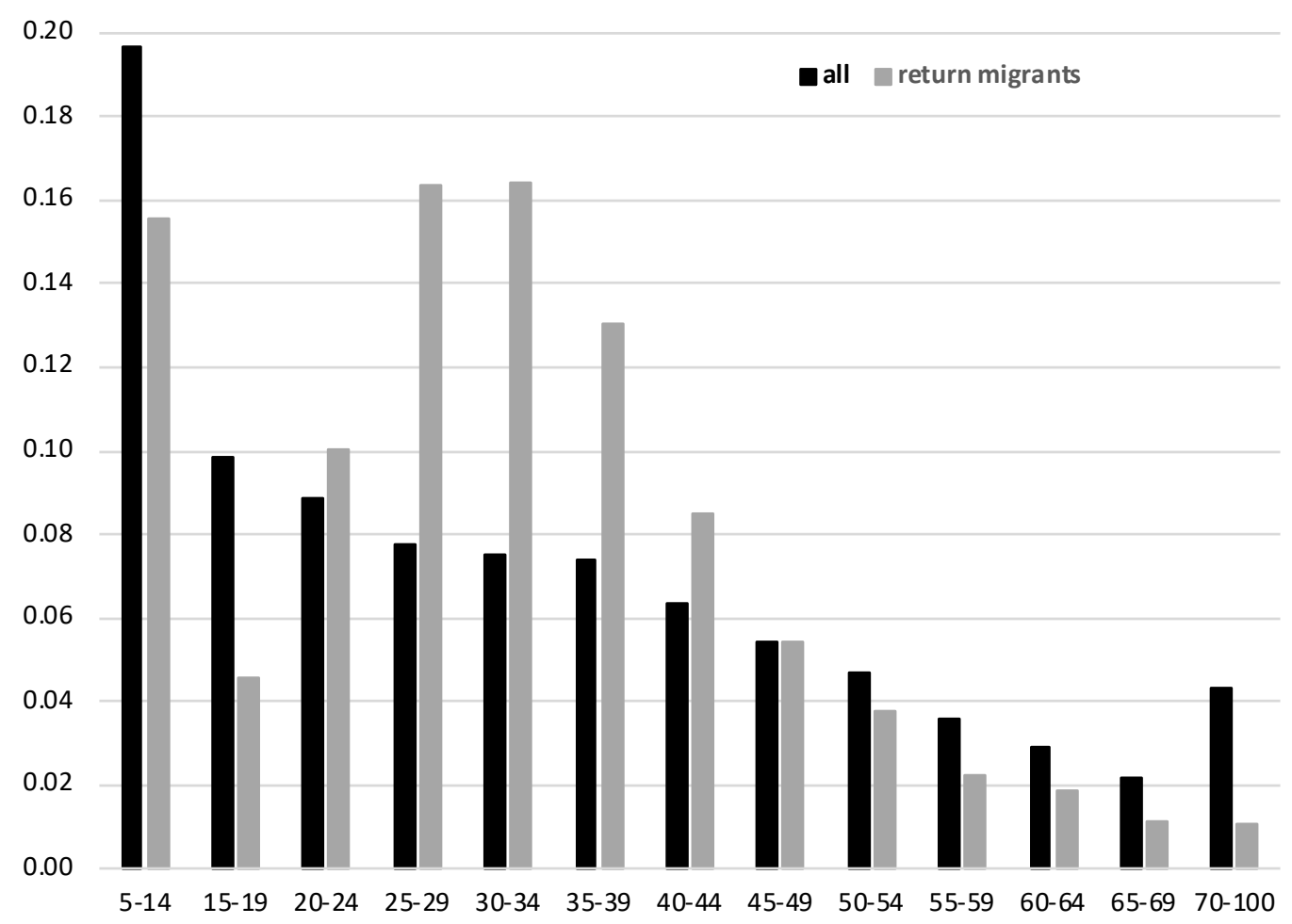

Authors' calculations using data from the 2010 Mexican Census. Return migrants are defined as those living in the US in June 2005, five years prior to the Census. Note that, in comparison to the overall population, return migrants are much more likely to be in the 25-39 age range and less likely to be under 20 and over 60 . 
Figure 6: Employment Share of Working-Age Population vs U.S. Employment Shock

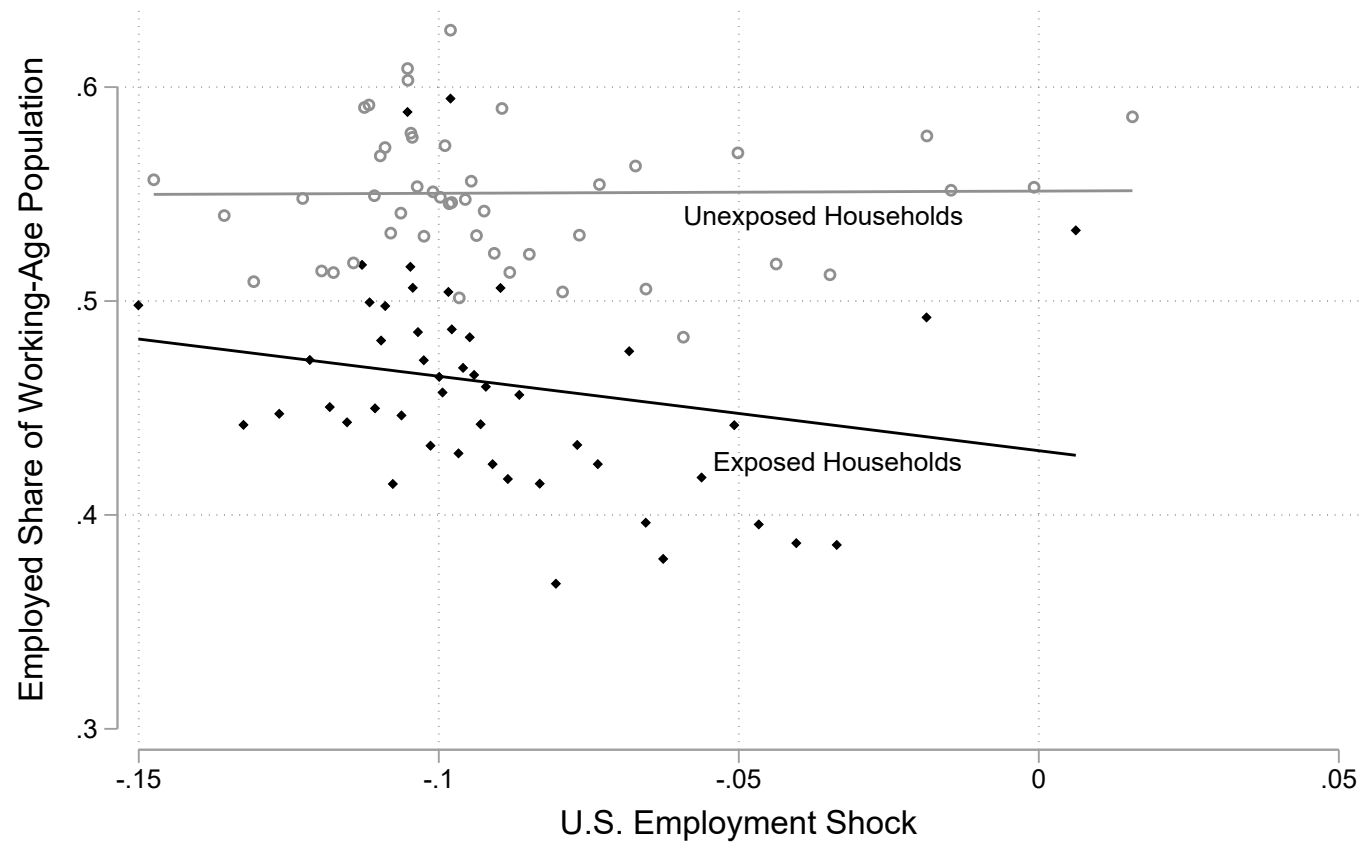

Points are binscatter means in 48 quantile bins.

This figure shows a binscatter plot of the variation identifying the main coefficient in column (1) of Table 6 . Each gray circle shows the employment share of the working-age population living in households with no US migrants (unexposed households) while each black diamond shows the employment share of the working-age population living in households with US migrants (exposed households). There is a strong negative relationship between the employment probability and the US employment shock for exposed households and essentially no relationship for unexposed households. 
Table 1: Summary Statistics

\begin{tabular}{lccccc}
\hline \hline & Obs & Mean & Std. Dev. & p10 & p90 \\
\hline Panel A: Shock Measure and Control Variables & & & & & \\
Exposure & 866 & 0.259 & 0.138 & 0.096 & 0.453 \\
US Employment Shock & 866 & -0.093 & 0.030 & -0.119 & -0.054 \\
New 287g Policy & 866 & 0.133 & 0.128 & 0.032 & 0.254 \\
Employment Policy & 866 & 0.174 & 0.137 & 0.047 & 0.360 \\
Trade Shock (\$1000s) & 866 & -8.479 & 70.479 & -13.747 & 4.706 \\
Non-tradable share of Employment & 866 & 0.722 & 0.175 & 0.467 & 0.902 \\
$\triangle$ Homicide Rate (per 1000) & 866 & 0.891 & 1.329 & 0.055 & 2.174
\end{tabular}

Panel B: Outcome Variables

Population growth and Migration - Mexican Population Census

Return Migration 2005-10/Pop200

$\begin{array}{lll}866 & 0.138\end{array}$

$\begin{array}{lll}866 & 0.028 & 0.017\end{array}$

$0.065 \quad 0.218$

Emigration 2005-10/Pop2005

$866 \quad 0.024$

0.021

$0.008 \quad 0.051$

$0.006 \quad 0.047$

Other Channels - Mexican Population Census

$\triangle$ Sex Ratio (F/M) 2005-10

$\triangle$ Less than primary education $2005-10$

866

$-0.046$

0.040

$-0.098$

$-0.002$

$\triangle$ Primary education 2005-10

$866-0.053$

0.020

$-0.079$

$-0.025$

$\triangle$ Secondary education $2005-10$

$866 \quad 0.004$

0.040

$-0.049$

0.051

$\triangle$ University education 2005-10

$866 \quad 0.035$

0.014

0.020

0.052

Households with Remittances 2010

$866 \quad 0.020$

0.012

0.006

0.036

$866 \quad 0.040$

0.036

0.008

0.093

Economic Outcomes - Mexican Economic Census

$\triangle$ Log Earninos per Hour 2004-09 864

$\triangle$ Epop 2004-09

866

0.230

0.477

$-0.243$

0.659

$\triangle$ Epop Men 2004-09

$866 \quad 0.014$

0.049

$-0.012$

0.058

$\triangle$ Epop Women 2004-09

$866 \quad 0.021$

0.054

$-0.030$

0.061

0.054

$\begin{array}{ll}-0.003 & 0.060\end{array}$

Economic Outcomes - Mexican Population Census

$\triangle$ Computer Ownership 2005-10 866

$\triangle$ Washing Machine Ownership 2005-10

866

0.066

0.034

0.026

0.113

$\triangle$ Refrigerator Ownership 2005-10

$866-0.068$

0.043

0.012

0.123

$\triangle$ TV Ownership 2005-10

$866 \quad 0.064$

0.045

0.008

0.127

$\triangle$ Attendance Rate (ages 6-12) 2005-10

$866 \quad 0.027$

0.039

$-0.003$

0.077

$\triangle$ Attendance Rate (ages 13-15) 2005-10

866

0.011

$-0.007$

0.018

$\triangle$ Attendance Rate (ages 16-18) 2005-10

$866 \quad 0.050$

0.040

0.003

0.106

$866 \quad 0.055$

0.037

0.008

0.102

This table shows summary statistics for all municipio-level outcomes, the main independent variable, and control variables used in the analyses. To construct dependent variables used in the regressions, we divide the listed variables by exposure. These values come from the underlying variable before this division. 
Table 2: Population Growth, Return Migration, and Emigration

\begin{tabular}{|c|c|c|c|c|c|c|c|c|c|}
\hline & \multicolumn{3}{|c|}{$\begin{array}{c}\text { Population Growth } \\
2005-10\end{array}$} & \multicolumn{3}{|c|}{$\begin{array}{l}\text { Return Migration } \\
2005-10\end{array}$} & \multicolumn{3}{|c|}{$\begin{array}{l}\text { Emigration } \\
2005-10\end{array}$} \\
\hline & $(1)$ & $(2)$ & $(3)$ & $(4)$ & $(5)$ & $(6)$ & $(7)$ & $(8)$ & $(9)$ \\
\hline US Employment Shock & $\begin{array}{c}-3.051^{* * *} \\
(0.673)\end{array}$ & $\begin{array}{c}-1.608 * * * \\
(0.617)\end{array}$ & $\begin{array}{c}-1.422^{* *} \\
(0.604)\end{array}$ & $\begin{array}{c}-0.235^{* *} \\
(0.083)\end{array}$ & $\begin{array}{c}-0.308 * * * \\
(0.073)\end{array}$ & $\begin{array}{c}-0.215^{* * *} \\
(0.078)\end{array}$ & $\begin{array}{l}0.259^{*} \\
(0.140)\end{array}$ & $\begin{array}{l}0.264^{*} \\
(0.140)\end{array}$ & $\begin{array}{c}0.349 * * \\
(0.146)\end{array}$ \\
\hline Pre-shock Outcome & & $\begin{array}{c}0.750^{* *} \\
(0.126)\end{array}$ & $\begin{array}{c}0.730 * * * \\
(0.130)\end{array}$ & & $\begin{array}{c}1.616^{* * * *} \\
(0.283)\end{array}$ & $\begin{array}{c}1.588^{* * *} \\
(0.283)\end{array}$ & & $\begin{array}{c}0.124^{* * *} \\
(0.025)\end{array}$ & $\begin{array}{c}0.112^{* * *} \\
(0.025)\end{array}$ \\
\hline New 287g Policy & & & $\begin{array}{l}0.253^{*} \\
(0.137)\end{array}$ & & & $\begin{array}{c}0.077^{* * *} \\
(0.018)\end{array}$ & & & $\begin{array}{c}0.027 \\
(0.026)\end{array}$ \\
\hline Employment Policy & & & $\begin{array}{c}0.087 \\
(0.096)\end{array}$ & & & $\begin{array}{l}-0.011 \\
(0.012)\end{array}$ & & & $\begin{array}{c}0.003 \\
(0.017)\end{array}$ \\
\hline Trade Shock & & & $\begin{array}{l}-0.131 \\
(0.178)\end{array}$ & & & $\begin{array}{l}0.021^{* *} \\
(0.009)\end{array}$ & & & $\begin{array}{c}0.051^{* * *} \\
(0.014)\end{array}$ \\
\hline $\begin{array}{l}\text { Non-tradable share } \\
\text { of Employment }\end{array}$ & & & $\begin{array}{c}-0.150 * * \\
(0.065)\end{array}$ & & & $\begin{array}{l}-0.012 \\
(0.008)\end{array}$ & & & $\begin{array}{c}0.011 \\
(0.013)\end{array}$ \\
\hline $\begin{array}{l}\text { Homicide Rate } \\
2005-10\end{array}$ & & & $\begin{array}{c}-22.307^{* *} \\
(10.508)\end{array}$ & & & $\begin{array}{c}-4.926 * * * \\
(1.066)\end{array}$ & & & $\begin{array}{c}-7.952^{* * * *} \\
(2.741)\end{array}$ \\
\hline State FE & Yes & Yes & Yes & Yes & Yes & Yes & Yes & Yes & Yes \\
\hline Observations & 866 & 866 & 866 & 866 & 866 & 866 & 866 & 866 & 866 \\
\hline R-squared & 0.177 & 0.571 & 0.581 & 0.311 & 0.513 & 0.538 & 0.269 & 0.269 & 0.316 \\
\hline
\end{tabular}

This table examines the effect of changes in US labor demand on the 2005-10 population growth, return migration to, and emigration from each Mexican source municipio. Note that outcome and pre-shock outcome variables are divided by exposure as in equation (8). We restrict attention to individuals age 15-64. Population growth is defined as the proportional change in population. Return migration is the number of individuals reporting living in the US 5 years prior to the relevant survey, divided by the municipio population in the survey year, while emigration is the number of household members who left for the US during the 5 years prior to the relevant survey, divided by the initial municipio population, measured using the roughly $10 \%$ long-form sample from the 2000 or 2010 Census (emigration information is not available in 2005). We use full-count tabulations from the 2000 or 2010 Mexican Census or 2005 Conteo to calculate population growth and return migration. All specifications in columns (1) to (6) use a GLS re-weighting procedure to address potential heteroskedasticity. The "Pre-shock Outcome" controls in columns (2), (5), and (8) are 2000-2005 population growth, 2000-2005 return migration, and 1995-2000 emigration, respectively. Columns (3), (6), and (9) additionally control for anti-immigrant employment legislation and new 287(g) agreements across U.S. CZs, trade shocks across municipios (divided by 1000000), share of employment in Mexico's non-tradable sector, and changes in homicide rates across municipios. All specifications control for Mexican state fixed effects, and standard errors clustered at the Mexican commuting zone level are shown in parentheses. ${ }^{* * *} \mathrm{p}<0.01,{ }^{* *} \mathrm{p}<0.05,{ }^{*} \mathrm{p}<0.1$ 
Table 3: Descriptive Statistics, 2010 Census

\begin{tabular}{lcc}
\hline \hline Characteristics & All & Return Migrants 2005-2010 \\
\hline Female & & \\
Married & $51.3 \%$ & $31.3 \%$ \\
& $42.0 \%$ & $57.9 \%$ \\
Education & & \\
$\quad$ Less than primary & $35.5 \%$ & $25.8 \%$ \\
$\quad$ Primary & $42.8 \%$ & $54.5 \%$ \\
$\quad$ Secondary & $14.5 \%$ & $15.5 \%$ \\
$\quad$ University & $7.2 \%$ & $4.2 \%$ \\
Employment & & \\
$\quad$ Employed & $50.1 \%$ & $62.9 \%$ \\
$\quad$ Self-employed & $27.7 \%$ & $31.6 \%$ \\
$\quad$ Paid employee & $69.1 \%$ & $63.6 \%$ \\
$\quad$ Unpaid worker & $3.2 \%$ & $4.7 \%$ \\
Unemployed & $2.4 \%$ & $5.5 \%$ \\
Not in the labor force & $47.5 \%$ & $31.6 \%$ \\
Hourly wage (yr 2000 pesos) & 19.64 & 18.90 \\
& & \\
\hline \hline
\end{tabular}

Authors' calculations using data from the 2010 Mexican Census. Return migrants are defined as those living in the US in June 2005, five years prior to the Census. Hourly wages calculated as (monthly earnings / 4.33) / (weekly hours) and deflated to year 2000 pesos using the consumer price index (INPC) from INEGI. Average hourly wages omit the top and bottom 1 percent of observations. Note that, in comparison to the overall population, return migrants are disproportionately male, more likely to be married, more likely to have primary school education, and more likely to be in the labor force. 
Table 4: Sex Ratio, Attainment, and Households Receiving Remittances

\begin{tabular}{|c|c|c|c|c|c|c|}
\hline & $\begin{array}{c}\triangle \text { Sex Ratio } \\
(\mathrm{F} / \mathrm{M}) 2005-10 \\
(1)\end{array}$ & $\begin{array}{c}\triangle \text { Less than Primary } \\
2005-10 \\
(2)\end{array}$ & $\begin{array}{c}\begin{array}{c}\triangle \text { Primary } \\
2005-10\end{array} \\
(3)\end{array}$ & $\begin{array}{c}\begin{array}{c}\triangle \text { Secondary } \\
2005-10\end{array} \\
(4)\end{array}$ & $\begin{array}{c}\begin{array}{c}\triangle \text { University } \\
2005-10\end{array} \\
(5)\end{array}$ & $\begin{array}{c}\begin{array}{c}\text { Household } \\
\text { Remittances } 2010\end{array} \\
(6)\end{array}$ \\
\hline New 287g Policy & $\begin{array}{l}-0.043 \\
(0.051)\end{array}$ & $\begin{array}{c}-0.090^{* * *} \\
(0.032)\end{array}$ & $\begin{array}{c}0.111^{* * *} \\
(0.041)\end{array}$ & $\begin{array}{l}-0.030 \\
(0.021)\end{array}$ & $\begin{array}{l}-0.003 \\
(0.016)\end{array}$ & $\begin{array}{c}0.005 \\
(0.027)\end{array}$ \\
\hline Trade Shock & $\begin{array}{c}-0.074^{* *} \\
(0.029)\end{array}$ & $\begin{array}{l}-0.028 \\
(0.018)\end{array}$ & $\begin{array}{c}0.280^{* * *} \\
(0.042)\end{array}$ & $\begin{array}{c}-0.181^{* * *} \\
(0.029)\end{array}$ & $\begin{array}{l}-0.016 \\
(0.022)\end{array}$ & $\begin{array}{c}0.046^{* *} \\
(0.022)\end{array}$ \\
\hline $\begin{array}{l}\text { Non-tradable share } \\
\text { of Employment }\end{array}$ & $\begin{array}{c}0.018 \\
(0.023)\end{array}$ & $\begin{array}{l}0.0005 \\
(0.014)\end{array}$ & $\begin{array}{c}0.083^{* * *} \\
(0.019)\end{array}$ & $\begin{array}{l}-0.006 \\
(0.012)\end{array}$ & $\begin{array}{c}-0.032^{* * *} \\
(0.007)\end{array}$ & $\begin{array}{l}0.022^{*} \\
(0.013)\end{array}$ \\
\hline $\begin{array}{l}\text { Homicide Rate } \\
2005-10\end{array}$ & $\begin{array}{c}10.085^{* * *} \\
(3.740)\end{array}$ & $\begin{array}{c}2.827 \\
(1.869)\end{array}$ & $\begin{array}{c}6.232^{* * *} \\
(2.184)\end{array}$ & $\begin{array}{c}0.541 \\
(0.980)\end{array}$ & $\begin{array}{l}-0.823 \\
(1.131)\end{array}$ & $\begin{array}{c}-4.990^{* *} \\
(2.505)\end{array}$ \\
\hline
\end{tabular}

This table examines the effect of changes in US labor demand on the 2005-10 change in the female to male sex ratio for the working age population (15-64), the 2005-10 change in the share of the working age population in each education level for each Mexican source municipio, and the share of households receiving remittances in 2010. Note that outcome and pre-shock outcome variables are divided by exposure as in equation (8). We measure the sex ratio and educational attainment using the 2000 or 2010 Mexican Census or 2005 Inter-Censal Count. We calculate the share of households receiving remittances as the number of households reporting receiving income from relatives living abroad divided by the municipio's total number of households in the Census year, using the 2000 or 2010 Mexican Census. All specifications in columns (1) to (6) use a GLS re-weighting procedure to address potential heteroskedasticity. The "Pre-shock Outcome" control in column (1) is the 2000-2005 change in the sex ratio. In columns (2)-(5) this control is the 2000-2005 change in the share of the municipio population with the listed level of schooling. In column (6), this control is the share of households receiving remittances in 2000. All specifications include controls for anti-immigrant employment legislation and new 287(g) agreements across U.S. CZs, trade shocks across municipios (divided by 1000000), share of employment in Mexico's non-tradable sector, changes in homicide rates across municipios, and Mexican state fixed effects. Standard errors clustered at the Mexican Commuting Zone level are shown in parentheses. ${ }^{* * *} \mathrm{p}<0.01,{ }^{* *} \mathrm{p}<0.05,{ }^{*} \mathrm{p}<0.1$ 
Table 5: Employment-to-population Ratio and Earnings per Hour

\begin{tabular}{|c|c|c|c|c|}
\hline & $\begin{array}{c}\triangle \mathrm{EPOP} \\
2004-09 \\
(1)\end{array}$ & $\begin{array}{c}\triangle \ln (\text { Hours }) \\
2004-09 \\
(2)\end{array}$ & $\begin{array}{c}\triangle \ln (\text { Earnings }) \\
2004-09 \\
(3)\end{array}$ & $\begin{array}{c}\triangle \ln (\text { EarnPerHour }) \\
2004-09 \\
(4)\end{array}$ \\
\hline \multicolumn{5}{|l|}{ Panel A. All } \\
\hline US Employment Shock & $\begin{array}{c}-0.440^{* *} \\
(0.210)\end{array}$ & $\begin{array}{c}-4.29^{* *} \\
(1.75)\end{array}$ & $\begin{array}{l}-6.06^{*} \\
(3.34)\end{array}$ & $\begin{array}{l}-2.08 \\
(2.78)\end{array}$ \\
\hline$\triangle \mathrm{EPOP}$ & $-0.463^{* * *}$ & & & \\
\hline 1999-04 & $(0.116)$ & & & \\
\hline$\triangle \ln ($ Hours $)$ & & $-0.14^{* *}$ & $0.30^{* *}$ & $0.44^{* * *}$ \\
\hline 1999-04 & & $(0.05)$ & $(0.12)$ & $(0.10)$ \\
\hline$\triangle \ln ($ Earnings $)$ & & $0.08 * * *$ & $-0.17^{* * *}$ & $-0.24^{* * *}$ \\
\hline 1999-04 & & $(0.03)$ & $(0.06)$ & $(0.05)$ \\
\hline
\end{tabular}

Panel B. Women

US Employment Shock $-0.847^{* * *}$

$(0.211)$

$\triangle \mathrm{EPOP} \quad-0.561^{* * *}$

Women 1999-04 (0.157)

Panel C. Men

US Employment Shock $\quad-0.080$

$(0.273)$

$\triangle \mathrm{EPOP}-0.357^{* * * *}$

Men 1999-04 (0.083)

\begin{tabular}{lcccc}
\hline State FE & Yes & Yes & Yes & Yes \\
Observations & 865 & 846 & 846 & 846 \\
\hline \hline
\end{tabular}

This table examines the effects of declines in US labor demand on the 2004-2009 change in the employment-to-population ratio, earnings, hours worked, and earnings per hours in each municipio, using employment, earnings and hours from the 1999, 2004 and 2009 Mexican Economic Census and population from the 2000 and 2010 Mexican Census and the 2005 Conteo. Note that the outcome and pre-shock outcome variables are divided by exposure as in equation (8). We trim the bottom and top 1 percent of the earnings distribution. All specifications in columns (1) to (4) use a GLS re-weighting procedure to address potential heteroskedasticity. All specifications include controls for anti-immigrant employment legislation and new $287(\mathrm{~g})$ agreements across U.S. CZs, trade shocks across municipios (divided by 1000000), share of employment in Mexico's non-tradable sector, changes in homicide rates across municipios, and Mexican state fixed effects. Standard errors clustered at the Mexican Commuting Zone level are shown in parentheses. ${ }^{* * *} \mathrm{p}<0.01,{ }^{* *} \mathrm{p}<0.05,{ }^{*} \mathrm{p}<0.1$ 
Table 6: Cross-Sectional Employment Analysis

\begin{tabular}{|c|c|c|c|}
\hline & $\begin{array}{c}\text { State FE } \\
(1)\end{array}$ & $\begin{array}{c}\text { State FE } \\
(2)\end{array}$ & $\begin{array}{c}\text { Municipio FE } \\
(3)\end{array}$ \\
\hline \multicolumn{4}{|l|}{ Panel A. All } \\
\hline US Employment Shock* $\mathbb{1}\left(\right.$ exposed $\left._{h}\right)$ & $\begin{array}{c}-0.224^{* * *} \\
(0.078)\end{array}$ & $\begin{array}{c}-0.166^{* *} \\
(0.075)\end{array}$ & $\begin{array}{l}-0.114 \\
(0.076)\end{array}$ \\
\hline $\mathbb{1}\left(\operatorname{exposed}_{h}\right)$ & $\begin{array}{c}-0.038^{* * *} \\
(0.008)\end{array}$ & $\begin{array}{c}-0.031^{* * *} \\
(0.007)\end{array}$ & $\begin{array}{c}-0.020^{* * *} \\
(0.007)\end{array}$ \\
\hline Observations & $33,270,660$ & $33,270,660$ & $33,270,660$ \\
\hline \multicolumn{4}{|l|}{ Panel B. Women } \\
\hline US Employment Shock* $\mathbb{1}\left(\operatorname{exposed}_{h}\right)$ & $\begin{array}{c}-0.352^{* * *} \\
(0.097)\end{array}$ & $\begin{array}{c}-0.268^{* * *} \\
(0.096)\end{array}$ & $\begin{array}{c}-0.235^{* *} \\
(0.098)\end{array}$ \\
\hline $\mathbb{1}\left(\operatorname{exposed}_{h}\right)$ & $\begin{array}{c}-0.048^{* * *} \\
(0.009)\end{array}$ & $\begin{array}{c}-0.039 * * * \\
(0.009)\end{array}$ & $\begin{array}{c}-0.026^{* * *} \\
(0.009)\end{array}$ \\
\hline Observations & $17,511,744$ & $17,511,744$ & $17,511,744$ \\
\hline \multicolumn{4}{|l|}{ Panel C. Men } \\
\hline US Employment Shock* $\mathbb{1}\left(\operatorname{exposed}_{h}\right)$ & $\begin{array}{l}-0.038 \\
(0.099)\end{array}$ & $\begin{array}{l}-0.005 \\
(0.097)\end{array}$ & $\begin{array}{c}0.055 \\
(0.093)\end{array}$ \\
\hline $\mathbb{1}\left(\operatorname{exposed}_{h}\right)$ & $\begin{array}{l}-0.005 \\
(0.009)\end{array}$ & $\begin{array}{l}-0.001 \\
(0.009)\end{array}$ & $\begin{array}{c}0.007 \\
(0.009)\end{array}$ \\
\hline Observations & $15,758,916$ & $15,758,916$ & $15,758,916$ \\
\hline
\end{tabular}

This table examines how labor supply behavior differs for households with and without US migrants in municipios facing different US shocks. We use cross-sectional data from the 2010 Census and define households exposed to US labor markets as those with either return migrants or with a household member living in the US. Columns (1) and (2) estimate the specification in Equation (11) while column (3) estimates a more general specification with municipio fixed effects. Column (2) show the results including controls for antiimmigrant employment legislation and new 287(g) agreements across U.S. CZs, trade shocks across municipios (divided by 1000000), share of employment in Mexico's non-tradable sector, and changes in homicide rates across municipios (and the municipio fixed effects in column (3) subsume all these controls). The negative coefficients for the interaction coefficient in all columns of Panel A imply that the employment probability is higher in exposed households in municipios connected to larger US employment declines. Panels B and C show that the relationship is driven almost entirely by women. Results are qualitatively similar to those in columns (1) and (2), though a bit less precise, when controlling for state $\times$ exposure status fixed effects. Standard errors clustered at the Mexican Commuting Zone level are shown in parentheses. ${ }^{* * *} \mathrm{p}<0.01,{ }^{* *} \mathrm{p}<0.05,{ }^{*} \mathrm{p}<0.1$ 


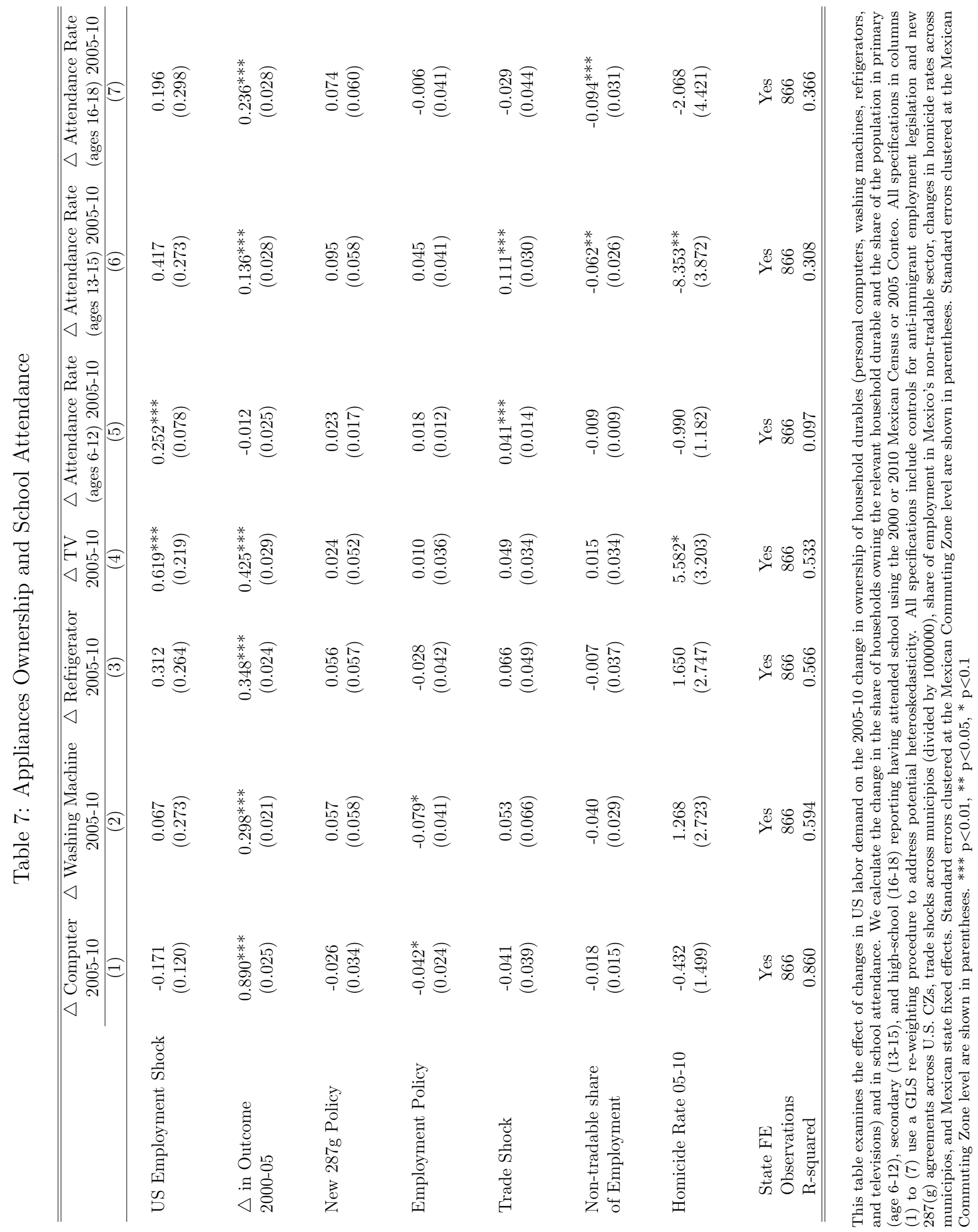




\section{A Appendix}

\section{A-1 Model Derivations}

To derive equation (3), start with the total derivative of $M_{s s}=M_{s} P_{s}(s)$, holding $M_{s}$ constant.

$$
d M_{s s}=M_{s}\left[\frac{\partial P_{s}(s)}{\partial v_{s}} d v_{s}+\sum_{d \neq s} \frac{\partial P_{s}(s)}{\partial v_{d}} d v_{d}\right]
$$

Then, evaluate the partial derivatives of the choice probabilities in (2).

$$
\begin{aligned}
\frac{\partial P_{s}(s)}{\partial v_{s}} & =\frac{\alpha \exp \left(\alpha v_{s}+n_{s s}\right)}{\sum_{d^{\prime}} \exp \left(\alpha v_{d^{\prime}}+n_{s d^{\prime}}\right)}-\alpha\left(\frac{\exp \left(\alpha v_{s}+n_{s s}\right)}{\sum_{d^{\prime}} \exp \left(\alpha v_{d^{\prime}}+n_{s d^{\prime}}\right)}\right)^{2} \\
& =\alpha P_{s}(s)\left(1-P_{s}(s)\right) \\
\frac{\partial P_{s}(s)}{\partial v_{d}} & =-\alpha \frac{\exp \left(\alpha v_{s}+n_{s s}\right) \exp \left(\alpha v_{d}+n_{s d}\right)}{\left(\sum_{d^{\prime}} \exp \left(\alpha v_{d^{\prime}}+n_{s d^{\prime}}\right)\right)^{2}} \quad \text { where } d \neq s \\
& =-\alpha P_{s}(s) P_{s}(d)
\end{aligned}
$$

Plugging these into (13) and simplifying yields (3).

To derive equation (6), start with its left hand side, and impose the assumptions listed just above (6). Assumption i) implies $\operatorname{Pr}\left(e m p_{d}\right)=E m p_{d}^{M} / M_{d}$, where $E m p_{d}^{M}$ is the number of employed Mexicans in $d$, and $M_{d} \equiv \sum_{s} M_{s d}$ is the Mexican population of $d$. Assumption ii) implies $\operatorname{Emp}_{d}^{M} / M_{d}=\gamma$, so

$$
d \operatorname{Pr}\left(e m p_{d}\right)=\gamma \frac{d E m p_{d}^{M}}{E m p_{d}^{M}} .
$$

Since total Mexican employment in $d$ is the sum of Mexican employment across industries $i$, we have the following identity.

$$
\frac{d E m p_{d}^{M}}{E m p_{d}^{M}} \equiv \sum_{i} \frac{E m p_{i d}^{M}}{E m p_{d}^{M}} \frac{d E m p_{i d}^{M}}{E m p_{i d}^{M}}
$$

Assumption iii) implies

$$
d E m p_{i d}^{M}=\frac{E m p_{i d}^{M}}{E m p_{i d}} d E m p_{i d}
$$

and assumption iv), $w_{d}=w$, in combination with the preceding expressions yields (6).

To derive (7), start with its left hand side and use the definition of $\gamma$ from above, the identity 
in (16), and the migration network term $\varphi=M_{s d} /\left(\sum_{d^{\prime} \neq s} M_{s d^{\prime}}\right)$ and simplify to yield (7).

$$
\begin{aligned}
\gamma \sum_{d \neq s} \varphi_{s d} \sum_{i} \frac{E m p_{i d}^{M}}{E m p_{d}^{M}} \cdot \frac{d E m p_{i d}}{E m p_{i d}} & =\frac{E m p_{d}^{M}}{M_{d}} \sum_{d \neq s} \frac{M_{s d}}{\left(\sum_{d^{\prime} \neq s} M_{s d^{\prime}}\right)} \frac{d E m p_{d}^{M}}{E m p_{d}^{M}} \\
& =\frac{1}{\sum_{d^{\prime} \neq s} M_{s d^{\prime}}} \sum_{d \neq s} \frac{M_{s d}}{M_{d}} d E m p_{d}^{M}
\end{aligned}
$$




\section{A-2 Data}

\section{A-2.1 Matrículas Consulares de Alta Seguridad}

We use a custom extract from the MCAS administrative dataset covering all the matrículas consulares issued in 2006 to Mexican-born individuals by place of birth in Mexico and place of residency in the US. Because this extract did not contain numerical identifiers for municipio or county, we needed to determine which municipio each record represented. We assigned each source municipio name an identifier to match those used by Mexico's Statistical Office (INEGI) and we assigned each US count a county-level FIPS code.

Mexican place of birth: The extract contained Mexican state and municipio of birth. However, the field for municipio of birth was sometimes reported by cardholders as their town or place of birth. After merging municipio names from INEGI's list, we ended up with 87 percent of the matrículas perfectly matched. For the remaining 13 percent of the matrículas, more than half (7 percent of the total) were from individuals reporting Mexico City as their place of birth. To address this issue, we aggregated municipios within Mexico City (Distrito Federal) in all Mexican datasets. For the remaining 6 percent we matched the information recorded in the municipio field to INEGI's identifiers by using a record linkage method (reclink2) in Stata, performing fuzzy matches. With these two procedures we were able to identify 95 percent of municipios in the dataset. Finally, we manually assigned places to municipios for 3 percent of the unmatched matrículas in the data, leaving us with 98 percent of the matrículas matched to a municipio.

US county of residency: The extract contained US state and county of residency. However, in some instances cardholders reported places or cities of residency, abbreviated or misspelled city names (i.e. LA for Los Angeles), or in very few instances county of residency that did not corresponded to the reported state of residence (i.e Charleston, South Dakota instead of Charleston, South Carolina). After merging county names using the FIP codes list from the US Census Bureau, we ended up with 88 percent of the matrículas perfectly matched. For the remaining unmatched cases, including those just mentioned, we manually coded the correct counties.

We aggregate destination counties to the commuting zone level, using the crosswalk in Dorn (2009). ${ }^{38}$ This provides us with information on the connections between each Mexican municipio and each US commuting zone.

\section{A-2.2 US Employment}

We measure changes in US labor demand using payroll employment from the County Business Patterns (CBP) data from 2006-2010. This dataset includes the universe of employment at business establishments in covered industries in each US county. We fill in employment estimates from uncovered industries, notably government and private household employees, using the American Community Survey (ACS) from IPUMS (Ruggles et al. 2017). Because our goal is to measure labor demand changes specific to Mexican-born workers employed in US industries, we also use data from the 2006 American Community Survey (ACS) to measure the share of the Mexican-born migrants employed in each industry prior to the Great Recession.

Because we want to measure changes in US labor demand at the local labor market level, we use commuting zones as our geographic unit of analysis in the US. We aggregate county-level em-

\footnotetext{
${ }^{38}$ https://www.ddorn.net/data.htm (file E7)
} 
ployment information from CBP and migrant destination data from MCAS to the commuting zone level using the crosswalk in Dorn (2009). ${ }^{39}$ We make manual adjustments to maintain consistent county boundaries over time. Because the most disaggregated sample available in the ACS is the Public Use Micro Areas (PUMA), we use another crosswalk from Dorn (2009) to match PUMAS to commuting zones. ${ }^{40}$ After these aggregations at the commuting zone level, we were able to use these two datasets to construct a weighted average of employment changes accounting for the industrial composition of Mexican employment in each US labor market.

\section{A-2.3 Demographic and Population Outcomes}

Return Migration: We define return migrants from the US to each Mexican municipio between 2005-2010 as individuals ages 15-64 living in Mexico during the 2010 Census reference period but who lived in the US five years before. These flows are identified through a question that asks respondents their country of residency five years prior to the Census year. Note that the count of return migrants does not include any individuals who were living in Mexico five years previously but who moved to the US and back within the five year window. We also calculate pre-shock return migration for the working age population between 2000-2005 using information from the the 2005 Conteo and the 2000 Mexican Census. To calculate these measures, we use official tabulations of the full-count 2010 Mexican Census and the 2005 Inter-Censal Count (Conteo), available at INEGI's website. We divided the 2005-2010 measure by the 2005 working age population and the 2000-2005 measure by the 2000 working age population in each municipio, using official tabulations of the full-count 2000 Mexican Census and 2005 Conteo, available at INEGI's website.

Emigration: We calculate emigration from each Mexican municipio to the US as the number of individuals ages 15-64 who reported leaving between 2005-2010 in the 2010 Mexican Census, using the 2010 Mexican Census supplemental sample questionnaire. This survey, available at the Mexican Statistical Office website (INEGI) contains an international migration module, conducted on a $10 \%$ sample of Mexican households in each Census year, asking respondents if anyone in the household went to live in the US during the previous five years. We also calculate pre-shock emigration for the working age population who reported leaving to the US between 1995-2000 using microdata from the 2000 Mexican Census, as the 2005 Conteo does not include information on emigration. We divided the 2005-2010 measure by the 2005 working age population and the 1995-2000 measure by the 2000 working age population in each municipio, using official tabulations of the full-count 2000 Mexican Census and 2005 Conteo, available at INEGI's website. Note that because the Mexican Census does not provide information on emigration of entire households, our emigration measure may be underestimated. Since we construct the emigration measure using a sample rather than the population, the return migration estimate is likely more reliable.

Population Changes: This measure is defined as the proportional change in the total number of Mexican individuals ages 15-64 in each Mexican municipio between 2005-2010 and between 20002005. We use official tabulations of the full-count 2000 and 2010 Mexican Census and the 2005 Conteo, available at INEGI's website.

Sex Ratio: This measure is defined as the ratio of the total number of Mexican women ages 15-64 in each Mexican municipio at the time of the Census or Conteo to the total number of men

\footnotetext{
${ }^{39}$ https://www.ddorn.net/data.htm (file E7)

${ }^{40}$ https: //www.ddorn.net/data.htm (file E5).
} 
ages 15-64 in each Mexican municipio at the same time. We calculate the female to male sex ratio using official tabulations of the full-count 2000 and 2010 Mexican Census and the 2005 Conteo, available at INEGI's website.

Educational Attainment: We measure the share of the municipio population with each education level as the total number of individuals ages 15-64 with that level of education at the time of the Census or Conteo, divided by the total working age population of the same municipio. The "less than primary education" category includes those with no schooling and with up to 4 years of primary education; individuals with primary education are those with primary and lower secondary completed; those with upper secondary completed are considered to have a secondary education; individuals with university education are those with at least some post-secondary schooling. We use official tabulations of the full-count 2000 and 2010 Mexican Census and the 2005 Conteo, available at INEGI's website.

Households receiving Remittances: We measure the share of households receiving remittances as the proportion of households in each municipio and Census year reporting receiving income from relatives abroad. We use 2000 and 2010 Mexican Census microdata from (Ruggles et al. 2017) to calculate this measure. Note that although the 2000 Census includes a question on the amount of remittances received by each surveyed household in Mexico, the 2010 Census reports only whether the household received any remittances. The relevant question is somewhat open-ended regarding the timeframe of remittance receipt, and enumerators encouraged respondents to report both regular and sporadic remittance receipt.

\section{A-2.4 Economic Outcomes}

Employment-to-population ratio: We calculate the employment-to-population ratio for each municipio as the share of the population ages 15-64 with formal employment. We measure the number of employed people in each municipio, separately for women and men, using full-count tabulations, available at INEGI's website, from the 1999, 2004, and 2009 Mexican Economic Census, which covers formal employment in Mexico excluding agriculture, livestock, forestry, mass transit, taxis, farmers' insurance funds, political organizations, and domestic employees. We divide this employment count by the working age population of the corresponding municipio using official tabulations of the full-count 2000 and 2010 Mexican Census and the 2005 Conteo available at INEGI's website.

Earnings per hour: We measure earnings per hour as the municipio's aggregate yearly earnings divided by the municipio's aggregate yearly hours worked, using full-count tabulations from the 1999, 2004, and 2009 Mexican Economic Census. This earnings measure therefore covers the same sectors as the employment measure. Note that earnings and hours worked are not available separately for men and women.

Appliance Ownership: We calculate appliance ownership as the proportion of households in each municipio reporting owning the relevant appliance at the time of the Census or Conteo, including a personal computer, a refrigerator, a washing machine, or a television. We use official tabulations of the full-count 2000 and 2010 Mexican Census and the 2005 Conteo, available at INEGI's website.

School Attendance Rate: We calculate the school attendance rates as the total number of children in each municipio attending primary (ages 6-12), lower secondary (ages 13-15) or upper secondary (ages 16-18) education at the time of the Census or Conteo, divided by the total population in that same age group and municipio. We use official tabulations of the full-count 2000 and 2010 Mexican Census and the 2005 Conteo, available at INEGI's website. 


\section{A-2.5 Controls}

Immigration policies: We use indicators for newly introduced state-level anti-immigrant employment legislation and indicators for new $287(\mathrm{~g})$ agreements allowing local officials to enforce federal immigration law, using information from the database complied by Bohn and Santillano (2012). Because these variables are measured at the state level, we use the crosswalk in (Dorn 2009) to map states to commuting zones. ${ }^{41}$ The control variables we include in the regressions are weighted averages of changes in the policy indicators with weights based on the destination distribution of migrants from the relevant municipio.

Trade Shocks: We focus on the effects of declining U.S. employment opportunities facing potential migrants from Mexico, but the Great Recession also reduced trade between Mexico and the U.S. Because we focuse on migration-related channels, the effects of declining trade could confound our analysis. We control for such trade effects by constructing municipio-level exposure to change in Mexican trade with the U.S. We begin by constructing industry-level changes in trade from Mexico to the U.S. per Mexican worker. We use trade data from the U.S. Census Bureau, provided in Stata format by Peter Schott. ${ }^{42}$ We aggregate these data from 10-digit HS products to 4-digit NAICS industries using the concordance from Pierce and Schott (2012) and calculate the change in trade value from the period 2001-2005 to the period 2006-2010. We measure initial Mexican employment using data from the 2004 Mexican Economic Census, which covers the vast majority of firms in sectors outside agriculture. ${ }^{43}$ For each municipio, we then generate a weighted average of these industry-level trade changes, where the weights reflect the municipio's 2004 distribution of tradable-industry employment across 4-digit NAICS industries, also calculated using the Economic Census. The weights sum to one across tradable industries, and we include an additional control for the nontradable share of employment in 2004 to address the incomplete shares problem (Borusyak et al. 2019).

Homicide Rate: We measure the number of homicides during 2005-2010 for each municipio divided by the 2005 population for the corresponding municipio, by using administrative yearly records from the Mexican Statistical Office (INEGI) and official tabulations of the full-count 2005 Conteo available at INEGI's website.

\footnotetext{
${ }^{41}$ https://www.ddorn.net/data.htm (file E8)

${ }^{42}$ https://sompks4.github.io/sub_data.html

${ }^{43}$ https://www.inegi.org.mx/app/saic/ Accessed March 27, 2020.
} 


\section{A-3 Additional empirical results}

\section{A-3.1 Shock variation conditional on exposure}

Figure A-1 shows a scatter plot relating the US employment shock to exposure, $\xi_{s}$, for the municipios in our sample. Although the two are positively related, with modestly higher average US employment shocks in municipios with higher exposure to the US labor market, the extensive variability in US employment shock within narrow ranges of exposure is clearly visible in the scatter plot. The R-squared for a linear regression relating the two quantities is only 0.019 .

Figure A-1: Exposure vs. US Employment Shock Measure

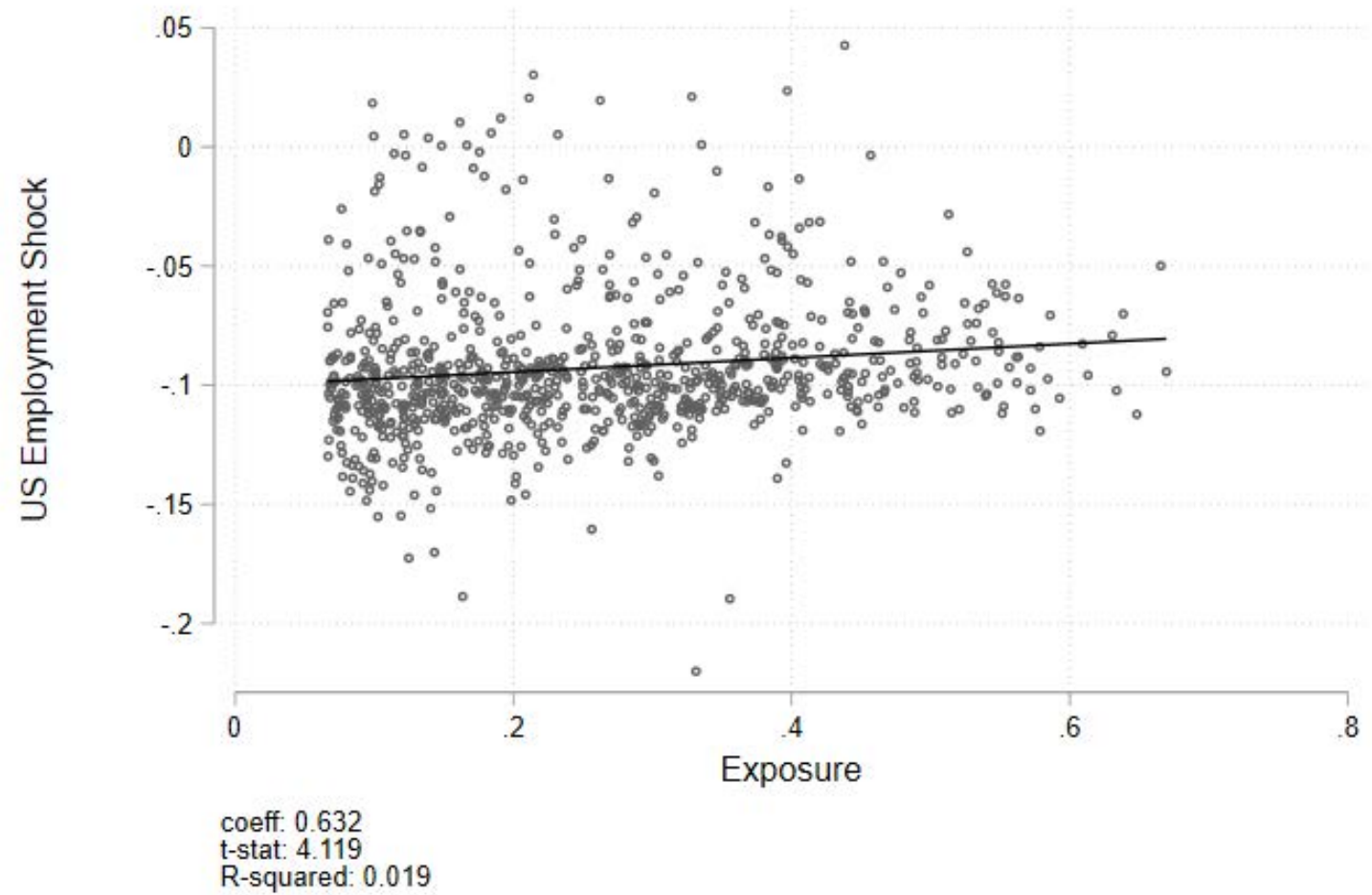

This figure shows the relationship between exposure to the US labor market and the UUS Employment Shock measure across Mexican municipios. 


\section{A-3.2 Subsets of controls}

Tables A-1 - A-5 show results paralleling those in Tables $4-7$, with different subsets of controls, as in Table 2. 


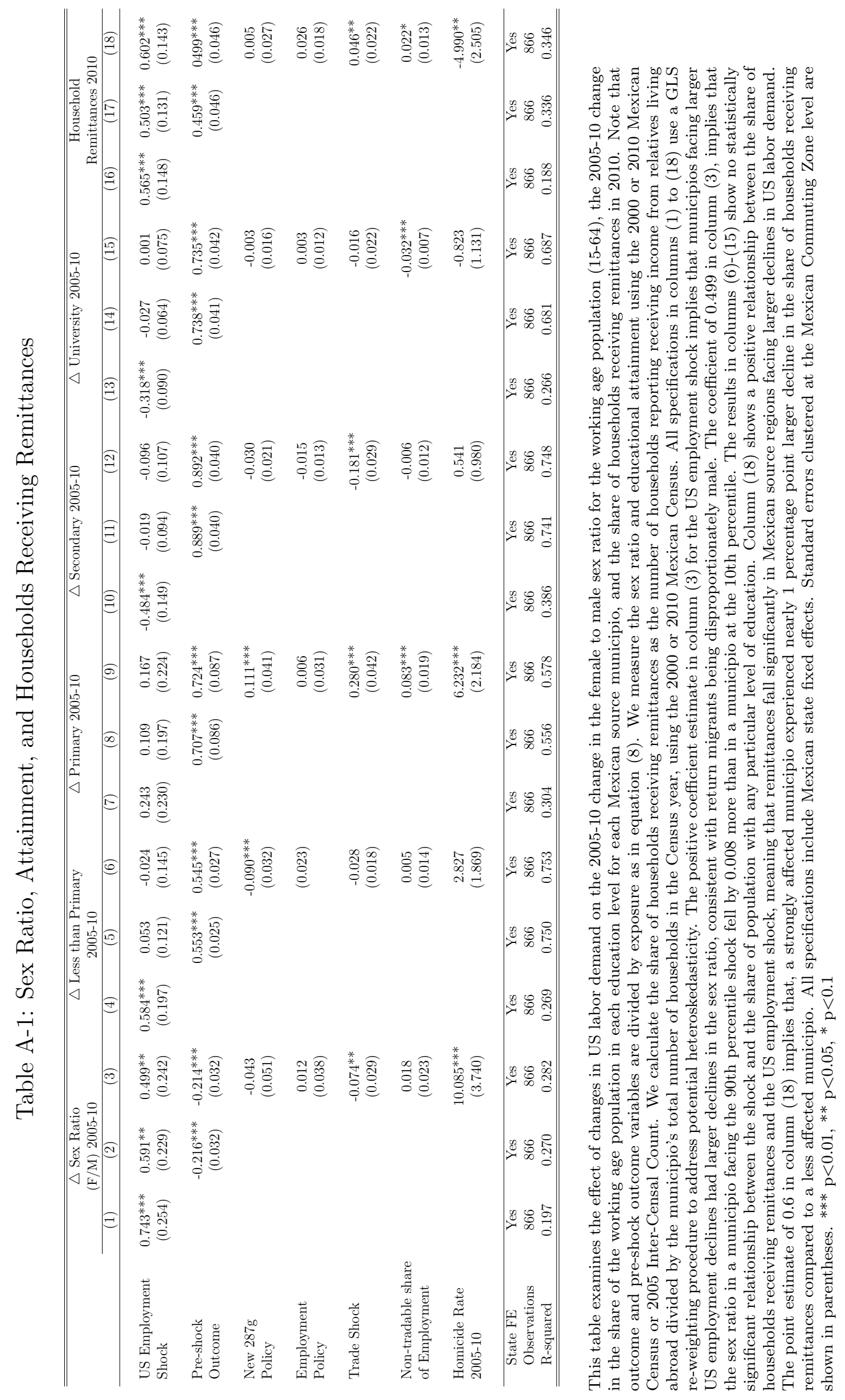




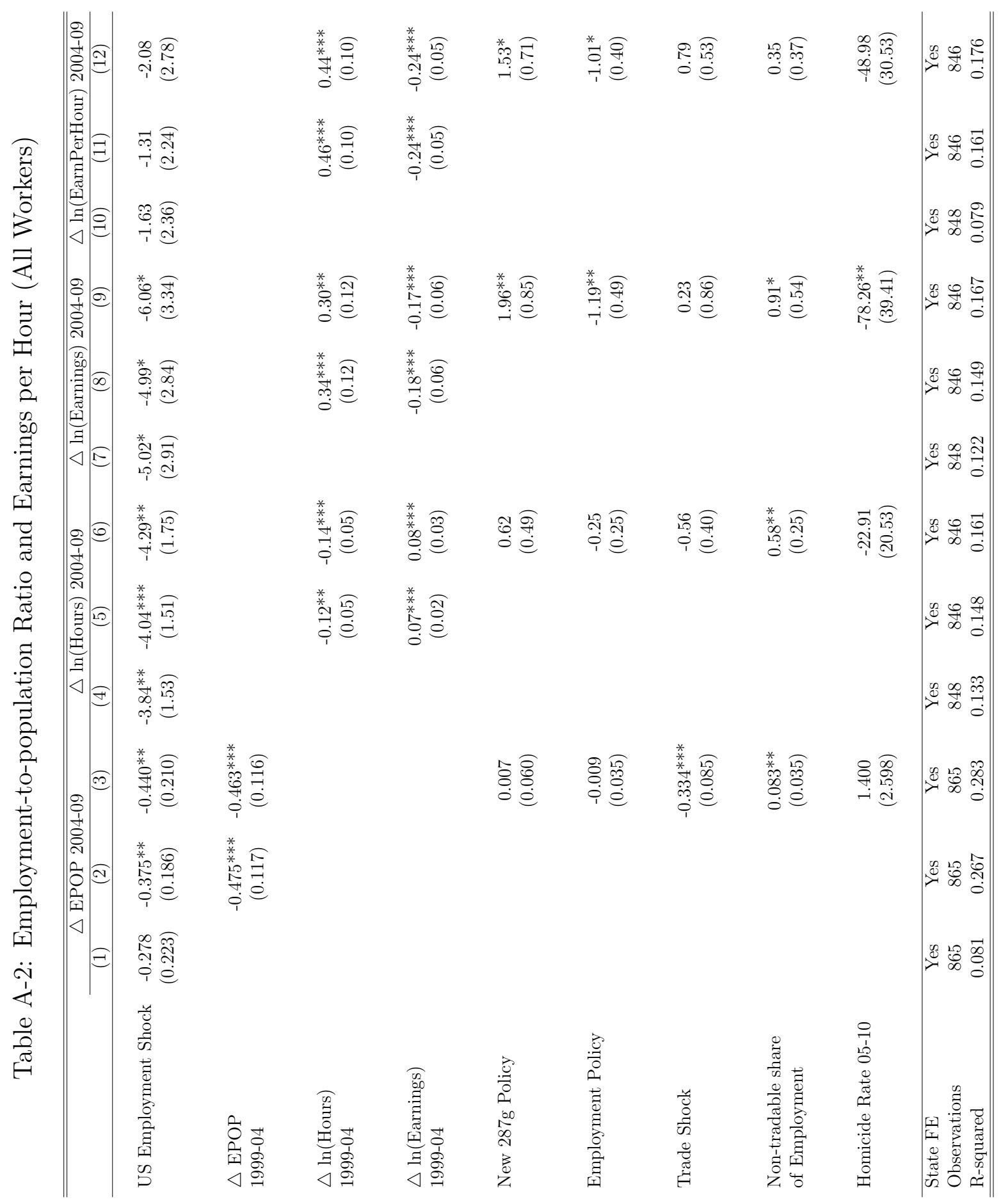

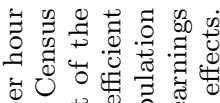

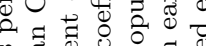

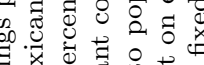

管

응 0 .

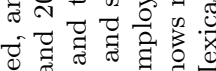

बै कै क ज

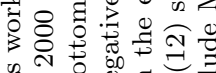

$\because$ 吃

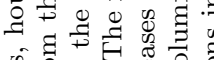

w

毒

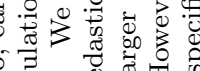

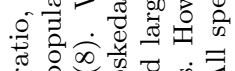

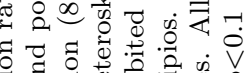

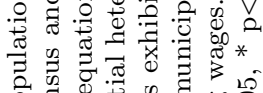

की

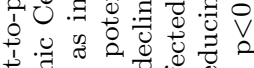

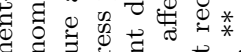

है क्ष

吾

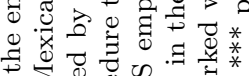

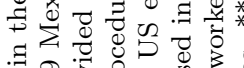

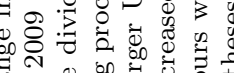

氜

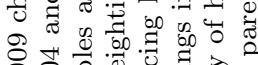

क्षे

+人

त

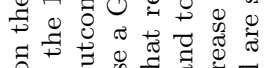

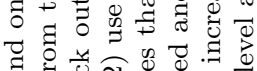

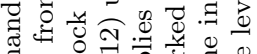

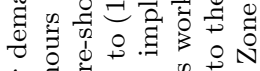

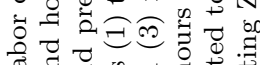

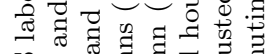

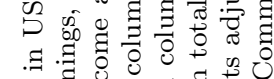

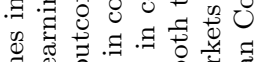

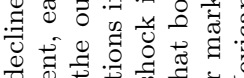

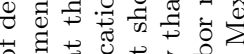

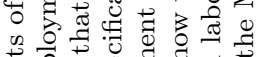

政

ब

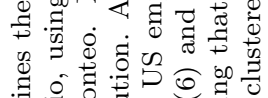

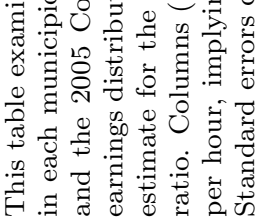


Table A-3: Employment-to-population Ratio by Gender

\begin{tabular}{|c|c|c|c|c|c|c|}
\hline & \multicolumn{3}{|c|}{$\begin{array}{c}\triangle \triangle \text { EPOP Women } \\
2004-09\end{array}$} & \multicolumn{3}{|c|}{$\begin{array}{l}\triangle \mathrm{EPOP} \text { Men } \\
2004-09\end{array}$} \\
\hline & $(1)$ & $(2)$ & $(3)$ & $(4)$ & $(5)$ & $(6)$ \\
\hline US Employment Shock & $\begin{array}{l}-0.366 \\
(0.247)\end{array}$ & $\begin{array}{c}-0.645^{* * *} \\
(0.193)\end{array}$ & $\begin{array}{c}-0.847^{* * *} \\
(0.211)\end{array}$ & $\begin{array}{l}-0.226 \\
(0.255)\end{array}$ & $\begin{array}{l}-0.193 \\
(0.223)\end{array}$ & $\begin{array}{l}-0.080 \\
(0.273)\end{array}$ \\
\hline $\begin{array}{l}\triangle \mathrm{EPOP} \\
1999-04\end{array}$ & & $\begin{array}{c}-0.569^{* * *} \\
(0.159)\end{array}$ & $\begin{array}{c}-0.561^{* * *} \\
(0.157)\end{array}$ & & $\begin{array}{c}-0.367^{* * *} \\
(0.085)\end{array}$ & $\begin{array}{c}-0.357^{* * *} \\
(0.083)\end{array}$ \\
\hline \multirow{2}{*}{ New 287g Policy } & & & $\begin{array}{l}-0.072 \\
(0.051)\end{array}$ & & & $\begin{array}{c}0.086 \\
(0.088)\end{array}$ \\
\hline & & & $\begin{array}{l}-0.051 \\
(0.035)\end{array}$ & & & $\begin{array}{c}0.044 \\
(0.045)\end{array}$ \\
\hline \multicolumn{7}{|l|}{ Employment Policy } \\
\hline \multirow{2}{*}{ Trade Shock } & & & $\begin{array}{c}0.027 \\
(0.103)\end{array}$ & & & $\begin{array}{c}-0.692^{* * *} \\
(0.126)\end{array}$ \\
\hline & & & $\begin{array}{l}0.057^{*} \\
(0.034)\end{array}$ & & & $\begin{array}{c}0.121^{* * *} \\
(0.046)\end{array}$ \\
\hline \multirow[t]{2}{*}{$\begin{array}{l}\text { Non-tradable share } \\
\text { of Employment }\end{array}$} & & & & & & \\
\hline & & & $\begin{array}{l}-1.680 \\
(2.785)\end{array}$ & & & $\begin{array}{c}4.292 \\
(3.475)\end{array}$ \\
\hline \multicolumn{7}{|l|}{ Homicide Rate 05-10 } \\
\hline State FE & Yes & Yes & Yes & Yes & Yes & Yes \\
\hline Observations & 866 & 865 & 865 & 866 & 865 & 865 \\
\hline R-squared & 0.104 & 0.308 & 0.313 & 0.060 & 0.209 & 0.255 \\
\hline
\end{tabular}

This table examines the effects of declines in US labor demand on the 2004-2009 change in the employment-to-population ratio for women and men in each municipio, using employment from the 1999, 2004 and 2009 Mexican Economic Census and population from the 2000 and 2010 Mexican Census and the 2005 Conteo. Note that the outcome and pre-shock outcome variables are divided by exposure as in equation (8). We trim the bottom and top 1 percent of the earnings distribution. All specifications in columns (1) to (6) use a GLS re-weighting procedure to address potential heteroskedasticity. The coefficient of -0.85 in colum (3) implies that a strongly affected municipio with average exposure to the US experienced a 1.4 percentage point larger increase in employment to population ratio among women compared to a similar municipio that was less affected. All specifications include Mexican state fixed effects. Standard errors clustered at the Mexican Commuting Zone level are shown in parentheses. ${ }^{* * *} \mathrm{p}<0.01,{ }^{* *} \mathrm{p}<0.05,{ }^{*} \mathrm{p}<0.1$ 


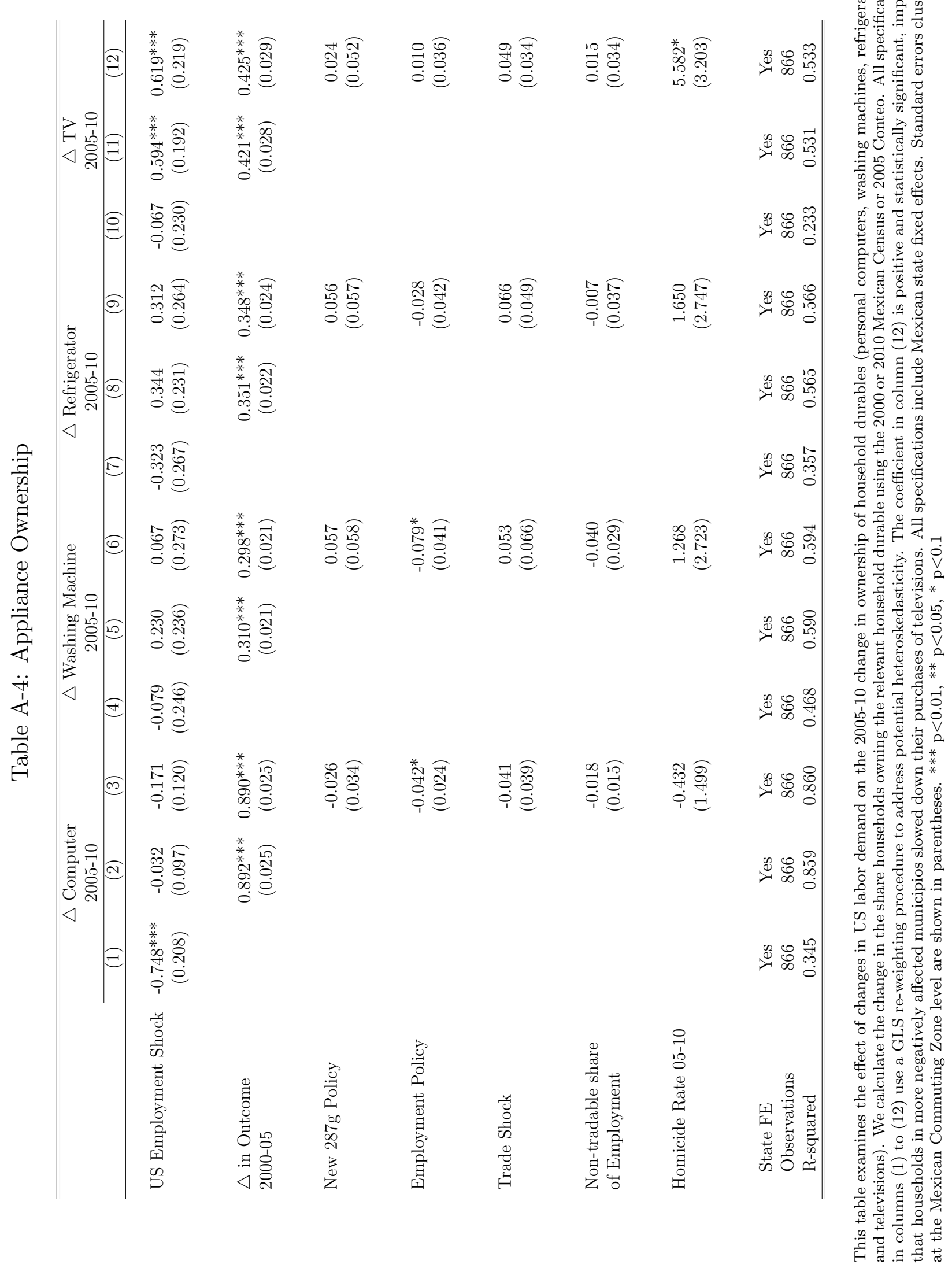


Table A-5: School Attendance

\begin{tabular}{|c|c|c|c|c|c|c|c|c|c|}
\hline & \multicolumn{3}{|c|}{$\begin{array}{c}\triangle \text { Attendance Rate } \\
\text { (ages 6-12) 2005-10 }\end{array}$} & \multicolumn{3}{|c|}{$\begin{array}{l}\triangle \text { Attendance Rate } \\
\text { (ages 13-15) 2005-10 }\end{array}$} & \multicolumn{3}{|c|}{$\begin{array}{l}\triangle \text { Attendance Rate } \\
\text { (ages 16-18) 2005-10 }\end{array}$} \\
\hline & $(1)$ & $(2)$ & $(3)$ & $(4)$ & $(5)$ & $(6)$ & $(7)$ & $(8)$ & (9) \\
\hline US Employment Shock & $\begin{array}{l}0.174^{* *} \\
(0.072)\end{array}$ & $\begin{array}{c}0.167 * * \\
(0.073)\end{array}$ & $\begin{array}{c}0.252^{* * *} \\
(0.078)\end{array}$ & $\begin{array}{l}-0.095 \\
(0.226)\end{array}$ & $\begin{array}{c}0.123 \\
(0.224)\end{array}$ & $\begin{array}{c}0.417 \\
(0.273)\end{array}$ & $\begin{array}{l}-0.279 \\
(0.270)\end{array}$ & $\begin{array}{c}0.095 \\
(0.253)\end{array}$ & $\begin{array}{c}0.196 \\
(0.298)\end{array}$ \\
\hline $\begin{array}{l}\triangle \text { in Outcome } \\
2000-05\end{array}$ & & $\begin{array}{l}-0.010 \\
(0.024)\end{array}$ & $\begin{array}{l}-0.012 \\
(0.025)\end{array}$ & & $\begin{array}{c}0.149 * * * \\
(0.028)\end{array}$ & $\begin{array}{c}0.136^{* * *} \\
(0.028)\end{array}$ & & $\begin{array}{c}0.250 * * * \\
(0.028)\end{array}$ & $\begin{array}{c}0.236^{* * *} \\
(0.028)\end{array}$ \\
\hline T. & & & $\begin{array}{c}0.023 \\
(0.017)\end{array}$ & & & $\begin{array}{c}0.095 \\
(0.058)\end{array}$ & & & $\begin{array}{c}0.074 \\
(0.060)\end{array}$ \\
\hline & & & $\begin{array}{c}0.018 \\
(0.012)\end{array}$ & & & $\begin{array}{c}0.045 \\
(0.041)\end{array}$ & & & $\begin{array}{l}-0.006 \\
(0.041)\end{array}$ \\
\hline Employment Policy & & & & & & & & & \\
\hline & & & $\begin{array}{c}0.041^{* * *} \\
(0.014)\end{array}$ & & & $\begin{array}{c}0.111^{* * *} \\
(0.030)\end{array}$ & & & $\begin{array}{l}-0.029 \\
(0.044)\end{array}$ \\
\hline & & & $\begin{array}{l}-0.009 \\
(0.009)\end{array}$ & & & $\begin{array}{c}-0.062^{* *} \\
(0.026)\end{array}$ & & & $\begin{array}{c}-0.094^{* * * *} \\
(0.031)\end{array}$ \\
\hline $\begin{array}{l}\text { Non-tradable share } \\
\text { of Employment }\end{array}$ & & & & & & & & & \\
\hline & & & $\begin{array}{l}-0.990 \\
(1.182)\end{array}$ & & & $\begin{array}{c}-8.353^{* *} \\
(3.872)\end{array}$ & & & $\begin{array}{l}-2.068 \\
(4.421)\end{array}$ \\
\hline Homicide Rate 05-10 & & & & & & & & & \\
\hline State FE & Yes & Yes & Yes & Yes & Yes & Yes & Yes & Yes & Yes \\
\hline Observations & 866 & 866 & 866 & 866 & 866 & 866 & 866 & 866 & 866 \\
\hline R-squared & 0.086 & 0.087 & 0.097 & 0.257 & 0.292 & 0.308 & 0.268 & 0.358 & 0.366 \\
\hline
\end{tabular}

This table examines the effect of changes in US labor demand on the 2005-10 change in school attendance. We calculate the change in the share of the population in primary (age 6-12), secondary (13-15), and high-school (16-18) reporting having attended school using the 2000 or 2010 Mexican Census or 2005 Conteo. All specifications in columns (1) to (9) use a GLS re-weighting procedure to address potential heteroskedasticity. The coefficient of 0.25 in column (3) implies that a municipio facing a 6.5 percentage point decline in US labor demand experienced 0.4 percentage point larger declines in school attendance for primary school children. This means that in municipios experiencing larger US employment declines, school attendance for primary school children fell more relative to municipios facing smaller employment shocks. All specifications include Mexican state fixed effects. Standard errors clustered at the Mexican Commuting Zone level are shown in parentheses. ${ }^{* * *} \mathrm{p}<0.01,{ }^{* *} \mathrm{p}<0.05,{ }^{*} \mathrm{p}<0.1$ 


\section{A-3.3 Unweighted Analysis}

Tables A-6 - A-11 show results paralleling those in the main text without the GLS weighting procedure used to address potential heteroskedasticity resulting from dividing the dependent variable by the municipio's estimated exposure to the US labor market. In nearly all cases, we reject the null hypothesis of homoskedastic errors at standard levels using a Breusch-Pagan test, the weighted and unweighted point estimates are very similar, and the weighted standard errors are smaller than the unweighted ones. 
Table A-6: Population Growth, Return Migration, and Emigration (unweighted)

\begin{tabular}{|c|c|c|c|c|c|c|c|c|c|}
\hline & \multicolumn{3}{|c|}{$\begin{array}{c}\text { Population Growth } \\
2005-10\end{array}$} & \multicolumn{3}{|c|}{$\begin{array}{c}\text { Return Migration } \\
2005-10\end{array}$} & \multicolumn{3}{|c|}{$\begin{array}{c}\text { Emigration } \\
2005-10\end{array}$} \\
\hline & $(1)$ & $(2)$ & $(3)$ & $(4)$ & $(5)$ & $(6)$ & $(7)$ & $(8)$ & $(9)$ \\
\hline US Employment Shock & $\begin{array}{c}-3.961^{* * *} \\
(0.987)\end{array}$ & $\begin{array}{l}-0.989 \\
(0.871)\end{array}$ & $\begin{array}{l}-0.954 \\
(0.916)\end{array}$ & $\begin{array}{c}-0.232^{* * *} \\
(0.090)\end{array}$ & $\begin{array}{c}-0.321^{* * *} \\
(0.079)\end{array}$ & $\begin{array}{c}-0.231^{* * *} \\
(0.084)\end{array}$ & $\begin{array}{c}0.238 * * \\
(0.146)\end{array}$ & $\begin{array}{c}0.239 * * \\
(0.145)\end{array}$ & $\begin{array}{c}0.322^{* *} \\
(0.154)\end{array}$ \\
\hline Pre-shock Outcome & & $\begin{array}{c}0.847^{* * *} \\
(0.177)\end{array}$ & $\begin{array}{c}0.833^{* * *} \\
(0.175)\end{array}$ & & $\begin{array}{c}1.698^{* * *} \\
(0.274)\end{array}$ & $\begin{array}{c}1.677^{* * *} \\
(0.273)\end{array}$ & & $\begin{array}{c}0.116^{* * *} \\
(0.027)\end{array}$ & $\begin{array}{c}0.108^{* * *} \\
(0.027)\end{array}$ \\
\hline New 287g Policy & & & $\begin{array}{c}0.105 \\
(0.193)\end{array}$ & & & $\begin{array}{c}0.079^{* * *} \\
(0.020)\end{array}$ & & & $\begin{array}{c}0.035 \\
(0.028)\end{array}$ \\
\hline Employment Policy & & & $\begin{array}{l}-0.101 \\
(0.113)\end{array}$ & & & $\begin{array}{l}-0.012 \\
(0.013)\end{array}$ & & & $\begin{array}{c}0.000 \\
(0.019)\end{array}$ \\
\hline Trade Shock & & & $\begin{array}{l}-0.209 \\
(0.271)\end{array}$ & & & $\begin{array}{c}0.020 \\
(0.009)\end{array}$ & & & $\begin{array}{l}0.054^{*} \\
(0.017)\end{array}$ \\
\hline $\begin{array}{l}\text { Non-tradable share } \\
\text { of Employment }\end{array}$ & & & $\begin{array}{c}-0.283^{* * *} \\
(0.121)\end{array}$ & & & $\begin{array}{l}-0.012 \\
(0.008)\end{array}$ & & & $\begin{array}{c}0.006 \\
(0.015)\end{array}$ \\
\hline Homicide Rate $05-10$ & & & $\begin{array}{l}-24.889 \\
(13.742)\end{array}$ & & & $\begin{array}{c}-4.950 * * * \\
(1.167)\end{array}$ & & & $\begin{array}{c}-7.411^{* * * *} \\
(2.705)\end{array}$ \\
\hline State FE & Yes & Yes & Yes & Yes & Yes & Yes & Yes & Yes & Yes \\
\hline Observations & 866 & 866 & 866 & 866 & 866 & 866 & 866 & 866 & 866 \\
\hline R-squared & 0.144 & 0.634 & 0.639 & 0.301 & 0.518 & 0.540 & 0.247 & 0.272 & 0.288 \\
\hline B-P het. p-val & 0.000 & 0.000 & 0.000 & 0.000 & 0.000 & 0.000 & 0.000 & 0.000 & 0.000 \\
\hline
\end{tabular}

This table examines the effect of changes in US labor demand on the 2005-10 population growth, return migration to, and emigration from each Mexican source municipio. Note that outcome and pre-shock outcome variables are divided by exposure as in equation (8). We restrict attention to individuals age 15-64. Population growth is defined as the proportional change in population. Return migration is the number of individuals reporting living in the US 5 years prior to the relevant survey, divided by the municipio population in the survey year, while emigration is the number of household members who left for the US during the 5 years prior to the relevant survey, divided by the initial municipio population, measured using the roughly $10 \%$ long-form sample from the 2000 or 2010 Census (emigration information is not available in 2005). We use full-count tabulations from the 2000 or 2010 Mexican Census or 2005 Conteo to calculate population growth and return migration. The "Pre-shock Outcome" controls in columns (2), (5), and (8) are 2000-2005 population growth, 2000-2005 return migration, and 1995-2000 emigration, respectively. Columns (3), (6), and (9) additionally control for anti-immigrant employment legislation and new 287(g) agreements across U.S. CZs, trade shocks across municipios (divided by 1000000), share of employment in Mexico's non-tradable sector, and changes in homicide rates across municipios. All specifications control for Mexican state fixed effects, and standard errors clustered at the Mexican commuting zone level are shown in parentheses. ${ }^{* * *} \mathrm{p}<0.01,{ }^{* *} \mathrm{p}<0.05,{ }^{*} \mathrm{p}<0.1$ 


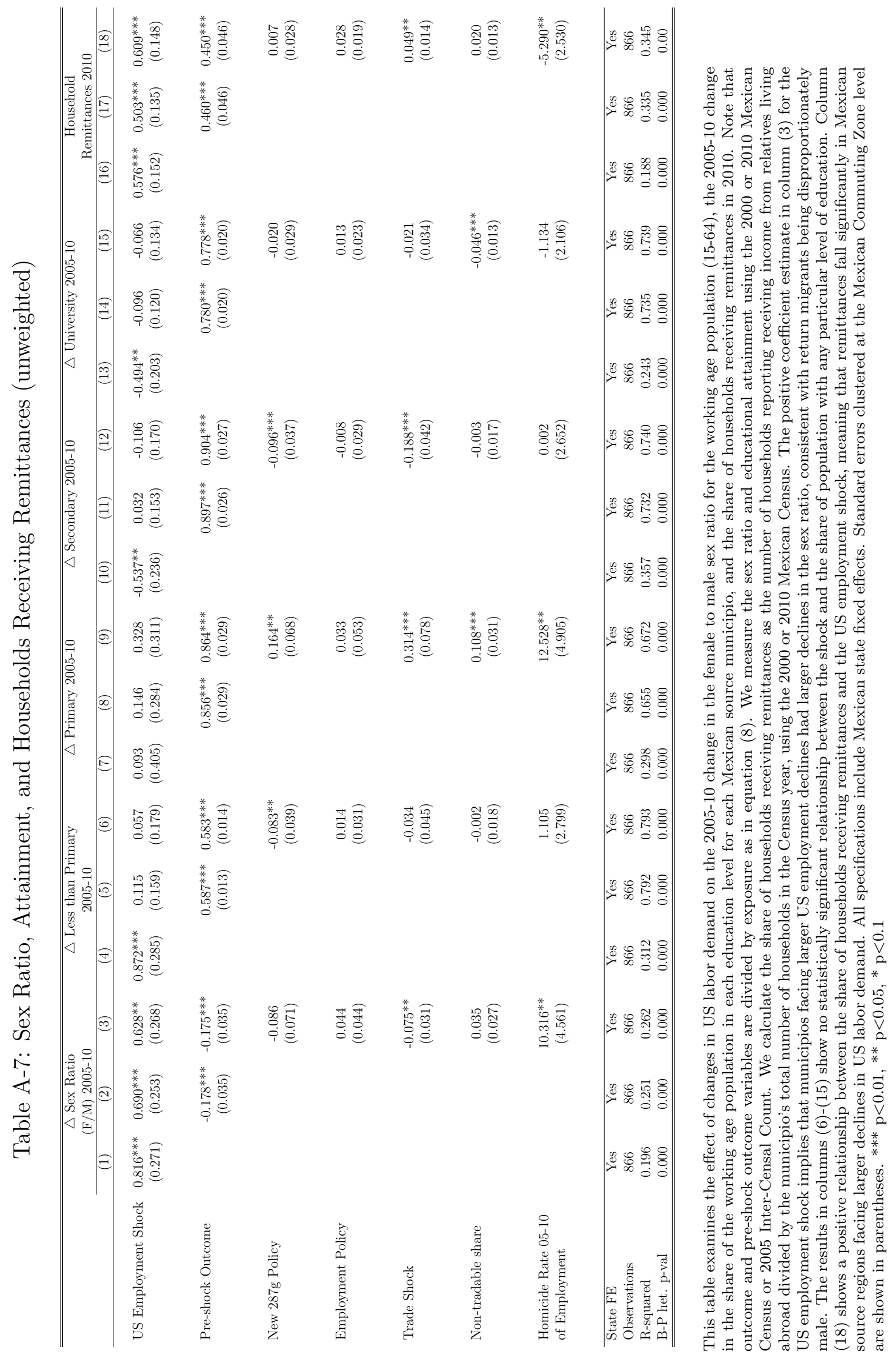




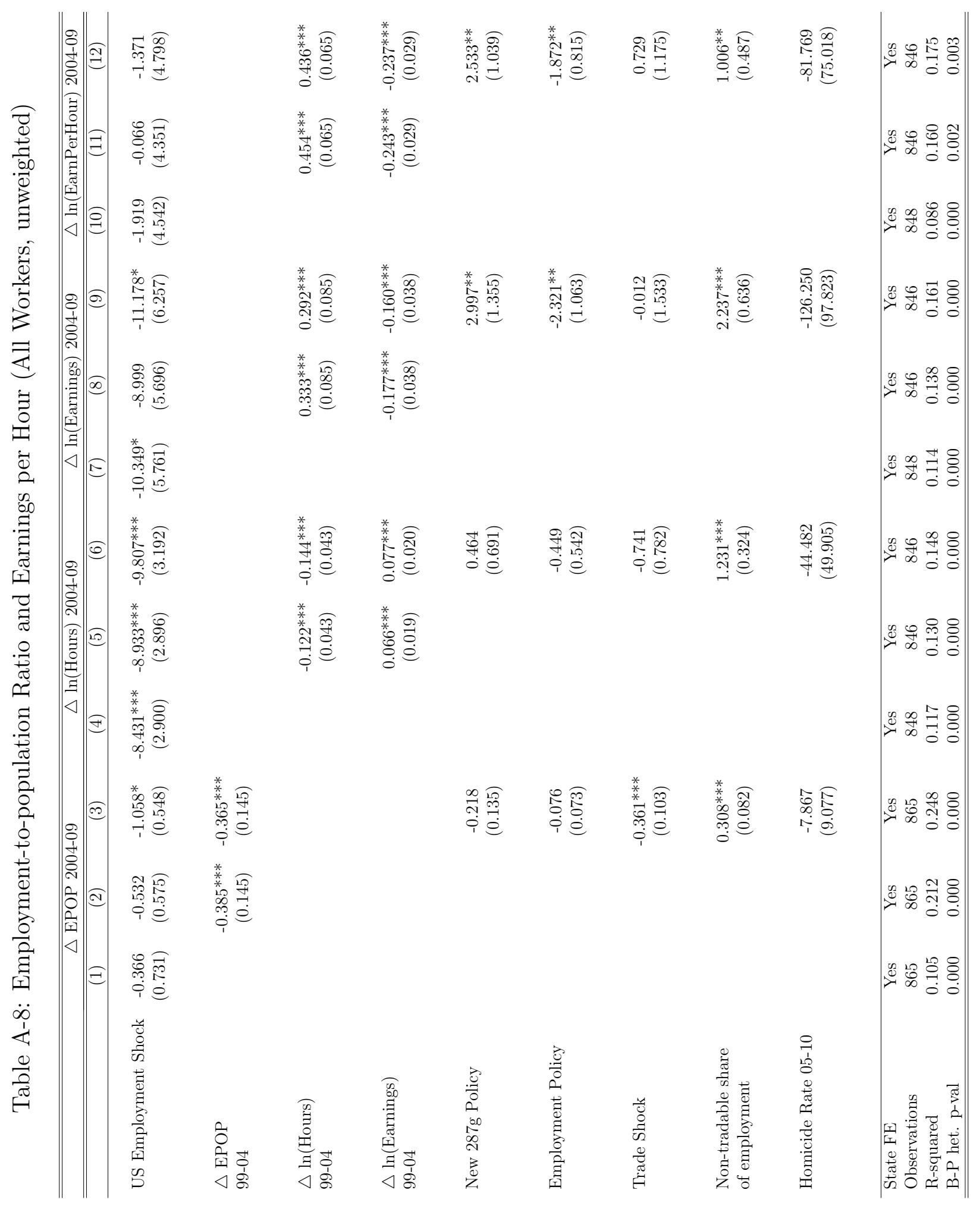

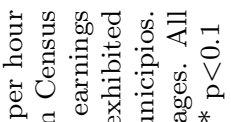

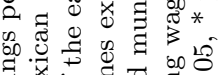

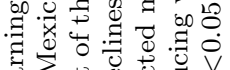

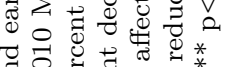

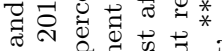

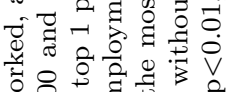
 言年 w

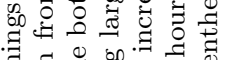

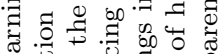

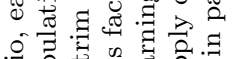

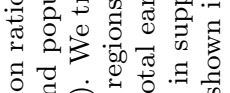

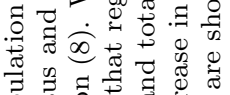

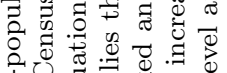

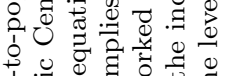

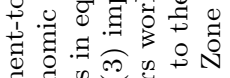

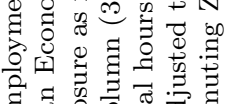

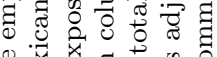
웡 a

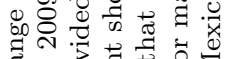

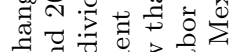

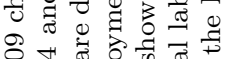

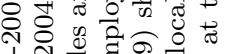

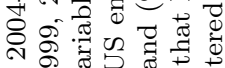
엉 a

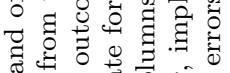

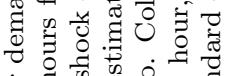

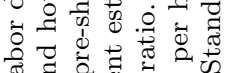
का 200 .

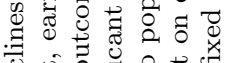

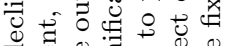
讨 s

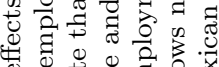
舟

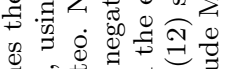
青. 영

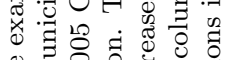
o

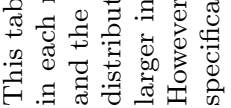


Table A-9: Employment-to-population Ratio by Gender (unweighted)

\begin{tabular}{|c|c|c|c|c|c|c|}
\hline & \multicolumn{3}{|c|}{$\begin{array}{l}\triangle \text { EPOP Women } \\
\text { 2004-09 }\end{array}$} & \multicolumn{3}{|c|}{$\begin{array}{l}\triangle \text { EPOP Men } \\
2004-09\end{array}$} \\
\hline & (1) & $(2)$ & $(3)$ & (4) & $(5)$ & $(6)$ \\
\hline US Employment Shock & $\begin{array}{l}-0.513 \\
(0.781)\end{array}$ & $\begin{array}{l}-0.895^{*} \\
(0.524)\end{array}$ & $\begin{array}{c}-1.453^{* * *} \\
(0.523)\end{array}$ & $\begin{array}{l}-0.179 \\
(0.744)\end{array}$ & $\begin{array}{l}-0.216 \\
(0.657)\end{array}$ & $\begin{array}{l}-0.646 \\
(0.631)\end{array}$ \\
\hline $\begin{array}{l}\triangle \mathrm{EPOP} \\
99-04\end{array}$ & & $\begin{array}{c}-0.546^{* * *} \\
(0.167)\end{array}$ & $\begin{array}{c}-0.525^{* * *} \\
(0.157)\end{array}$ & & $\begin{array}{c}-0.286^{* *} \\
(0.115)\end{array}$ & $\begin{array}{c}-0.272^{* *} \\
(0.108)\end{array}$ \\
\hline New 287g Policy & & & $\begin{array}{c}-0.270^{* *} \\
(0.136)\end{array}$ & & & $\begin{array}{l}-0.143 \\
(0.145)\end{array}$ \\
\hline Employment Policy & & & $\begin{array}{l}-0.104 \\
(0.072)\end{array}$ & & & $\begin{array}{l}-0.035 \\
(0.082)\end{array}$ \\
\hline Trade Shock & & & $\begin{array}{c}0.024 \\
(0.107)\end{array}$ & & & $\begin{array}{c}-0.736^{* * *} \\
(0.147)\end{array}$ \\
\hline $\begin{array}{l}\text { Non-tradable share } \\
\text { of Employment }\end{array}$ & & & $\begin{array}{c}0.239^{* * *} \\
(0.071)\end{array}$ & & & $\begin{array}{c}0.367^{* * *} \\
(0.100)\end{array}$ \\
\hline Homicide Rate $05-10$ & & & $\begin{array}{l}-11.795 \\
(9.552)\end{array}$ & & & $\begin{array}{l}-4.038 \\
(8.630)\end{array}$ \\
\hline State FE & Yes & Yes & Yes & Yes & Yes & Yes \\
\hline Observations & 866 & 865 & 865 & 866 & 865 & 865 \\
\hline R-squared & 0.129 & 0.303 & 0.326 & 0.082 & 0.158 & 0.205 \\
\hline B-P het. p-val & 0.000 & 0.000 & 0.000 & 0.000 & 0.000 & 0.000 \\
\hline
\end{tabular}

This table examines the effects of declines in US labor demand on the 2004-2009 change in the employment-to-population ratio for women and men in each municipio, using employment from the 1999, 2004 and 2009 Mexican Economic Census and population from the 2000 and 2010 Mexican Census and the 2005 Conteo. Note that the outcome and pre-shock outcome variables are divided by exposure as in equation (8). We trim the bottom and top 1 percent of the earnings distribution. The negative coefficient in colum (3) implies that a strongly affected municipio experienced larger increase in employment to population ratio among women compared to a similar municipio that was less affected. All specifications include Mexican state fixed effects. Standard errors clustered at the Mexican Commuting Zone level are shown in parentheses. ${ }^{* * *} \mathrm{p}<0.01,{ }^{* *} \mathrm{p}<0.05,{ }^{*} \mathrm{p}<0.1$ 


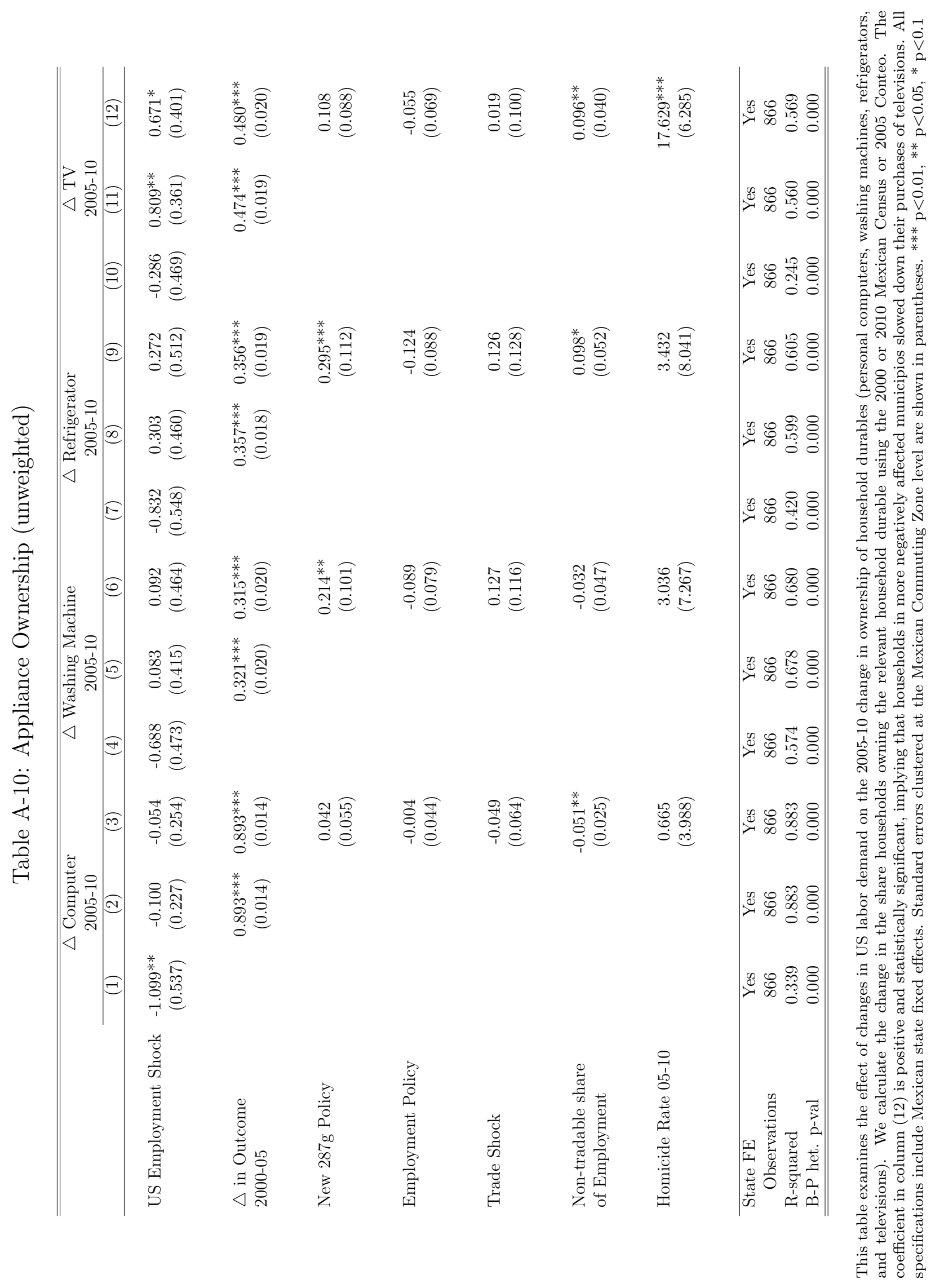


Table A-11: School Attendance (unweighted)

\begin{tabular}{|c|c|c|c|c|c|c|c|c|c|}
\hline & \multicolumn{3}{|c|}{$\begin{array}{l}\triangle \text { Attendance Rate } \\
\text { (ages 6-12) 2005-10 }\end{array}$} & \multicolumn{3}{|c|}{$\begin{array}{l}\triangle \text { Attendance Rate } \\
\text { (ages 13-15) 2005-10 }\end{array}$} & \multicolumn{3}{|c|}{$\begin{array}{l}\triangle \text { Attendance Rate } \\
\text { (ages 16-18) 2005-10 }\end{array}$} \\
\hline & $(1)$ & $(2)$ & $(3)$ & $(4)$ & $(5)$ & $(6)$ & $(7)$ & $(8)$ & $(9)$ \\
\hline US Employment Shock & $\begin{array}{c}0.102 \\
(0.101)\end{array}$ & $\begin{array}{c}0.107 \\
(0.102)\end{array}$ & $\begin{array}{l}0.211^{*} \\
(0.114)\end{array}$ & $\begin{array}{l}-0.041 \\
(0.332)\end{array}$ & $\begin{array}{c}0.298 \\
(0.325)\end{array}$ & $\begin{array}{c}0.582 \\
(0.361)\end{array}$ & $\begin{array}{l}-0.003 \\
(0.431)\end{array}$ & $\begin{array}{c}0.518 \\
(0.399)\end{array}$ & $\begin{array}{c}0.646 \\
(0.445)\end{array}$ \\
\hline $\begin{array}{l}\triangle \text { in Outcome } \\
2000-05\end{array}$ & & $\begin{array}{c}0.005 \\
(0.014)\end{array}$ & $\begin{array}{c}0.005 \\
(0.014)\end{array}$ & & $\begin{array}{c}0.164^{* * *} \\
(0.022)\end{array}$ & $\begin{array}{c}0.153^{* * *} \\
(0.022)\end{array}$ & & $\begin{array}{c}0.286^{* * *} \\
(0.023)\end{array}$ & $\begin{array}{c}0.272^{* * *} \\
(0.024)\end{array}$ \\
\hline New 287g Policy & & & $\begin{array}{c}0.005 \\
(0.025)\end{array}$ & & & $\begin{array}{c}0.117 \\
(0.078)\end{array}$ & & & $\begin{array}{c}0.142 \\
(0.097)\end{array}$ \\
\hline Employment Policy & & & $\begin{array}{l}0.035^{*} \\
(0.019)\end{array}$ & & & $\begin{array}{c}0.034 \\
(0.062)\end{array}$ & & & $\begin{array}{l}-0.032 \\
(0.076)\end{array}$ \\
\hline Trade Shock & & & $\begin{array}{l}0.050^{*} \\
(0.028)\end{array}$ & & & $\begin{array}{c}0.106 \\
(0.090)\end{array}$ & & & $\begin{array}{l}-0.037 \\
(0.111)\end{array}$ \\
\hline $\begin{array}{l}\text { Non-tradable share } \\
\text { of Emplyment }\end{array}$ & & & $\begin{array}{l}-0.009 \\
(0.011)\end{array}$ & & & $\begin{array}{c}-0.090^{* *} \\
(0.037)\end{array}$ & & & $\begin{array}{c}-0.131^{* * *} \\
(0.045)\end{array}$ \\
\hline Homicide Rate 05-10 & & & $\begin{array}{l}-0.810 \\
(1.773)\end{array}$ & & & $\begin{array}{l}-8.997 \\
(5.641)\end{array}$ & & & $\begin{array}{l}-5.929 \\
(6.963)\end{array}$ \\
\hline State FE & Yes & Yes & Yes & Yes & Yes & Yes & Yes & Yes & Yes \\
\hline Observations & 866 & 866 & 866 & 866 & 866 & 866 & 866 & 866 & 866 \\
\hline R-squared & 0.093 & 0.093 & 0.101 & 0.221 & 0.269 & 0.280 & 0.241 & 0.358 & 0.367 \\
\hline B-P het. p-val & 0.181 & 0.069 & 0.035 & 0.000 & 0.000 & 0.000 & 0.000 & 0.000 & 0.000 \\
\hline
\end{tabular}

This table examines the effect of changes in US labor demand on the 2005-10 change in school attendance. We calculate the change in the share of the population in primary (age 6-12), secondary (13-15), and high-school (16-18) reporting having attended school using the 2000 or 2010 Mexican Census or 2005 Conteo. The positive coefficient in column (3) implies that in municipios experiencing larger US employment declines, school attendance for primary school children fell more relative to municipios facing smaller employment shocks. All specifications include Mexican state fixed effects. Standard errors clustered at the Mexican Commuting Zone level are shown in parentheses. ${ }^{* * *} \mathrm{p}<0.01,{ }^{* *} \mathrm{p}<0.05,{ }^{*} \mathrm{p}<0.1$ 


\section{A-3.4 Mexican Commuting Zone Analysis for Labor Market Outcomes}

For consistency with the rest of the analysis, the labor market outcome results in Table 5 use Mexican municipio as the unit of analysis. Here, we provide a parallel analysis using Mexican commuting zones as the unit of analysis, in order to address the possibility that municipios in the same commuting zone may be part of an integrated labor market in equilibrium. We define Mexican commuting zones following Atkin (2016), and impose the same sample restrictions to commuting zones that we did to municipios in the main text: at least 5,000 residents in 2005, exposure $\xi_{s}>0.066$ (the 25th percentile), and at least 100 MCAS cards in 2006. This yields a sample of 741 Mexican commuting zones (and 723 with information in the Economic Census). The results in Table A-12 are extremely similar to those in Table 5, showing that the choice of Mexican market aggregation does not substantially affect our findings. 
Table A-12: Employment-to-population Ratio and Earnings per Hour

\begin{tabular}{|c|c|c|c|c|}
\hline & $\begin{array}{c}\triangle \mathrm{EPOP} \\
2004-09 \\
(1)\end{array}$ & $\begin{array}{c}\triangle \ln (\text { Hours }) \\
2004-09 \\
(2)\end{array}$ & $\begin{array}{c}\triangle \ln (\text { Earnings }) \\
2004-09 \\
(3)\end{array}$ & $\begin{array}{c}\ln (\text { EarnPerHour }) \\
2004-09 \\
(4)\end{array}$ \\
\hline \multicolumn{5}{|l|}{ Panel A. All } \\
\hline US Employment Shock & $\begin{array}{c}-0.539^{* *} \\
(0.215)\end{array}$ & $\begin{array}{c}-5.12^{* * *} \\
(1.64)\end{array}$ & $\begin{array}{l}-5.73^{*} \\
(3.08)\end{array}$ & $\begin{array}{l}-0.77 \\
(2.58)\end{array}$ \\
\hline$\triangle \mathrm{EPOP}$ & $-0.483^{* * *}$ & & & \\
\hline 1999-04 & $(0.107)$ & & & \\
\hline$\triangle \ln ($ Hours $)$ & & $-0.17^{* *}$ & $0.25^{*}$ & $0.43^{* * *}$ \\
\hline 1999-04 & & $(0.05)$ & $(0.13)$ & $(0.10)$ \\
\hline$\triangle \ln ($ Earnings $)$ & & $0.06^{* *}$ & $-0.17^{* *}$ & $-0.22^{* * *}$ \\
\hline 1999-04 & & $(0.03)$ & $(0.07)$ & $(0.05)$ \\
\hline
\end{tabular}

Panel B. Women

US Employment Shock $-0.992^{* * *}$

(0.290)

$\triangle \mathrm{EPOP} \quad-0.614^{* * *}$

Women 1999-04 (0.155)

Panel C. Men

US Employment Shock $\quad-0.263$

$(0.244)$

$\triangle \mathrm{EPOP} \quad-0.360^{* * *}$

Men 1999-04 (0.086)

\begin{tabular}{lcccc}
\hline State FE & Yes & Yes & Yes & Yes \\
Observations & 741 & 723 & 723 & 723 \\
\hline \hline
\end{tabular}

This table examines the effects of declines in US labor demand on the 2004-2009 change in the employment-to-population ratio, earnings, hours worked, and earnings per hours in each Mexican commuting zone level, using employment, earnings and hours from the 1999, 2004 and 2009 Mexican Economic Census and population from the 2000 and 2010 Mexican Census and the 2005 Conteo. Note that the outcome and pre-shock outcome variables are divided by exposure as in equation (8). We trim the bottom and top 1 percent of the earnings distribution. All specifications in columns (1) to (4) use a GLS re-weighting procedure to address potential heteroskedasticity. All specifications include controls for anti-immigrant employment legislation and new 287(g) agreements across U.S. CZs, trade shocks across municipios (divided by 1000000), share of employment in Mexico's non-tradable sector, changes in homicide rates across municipios, and Mexican state fixed effects. Robust standard errors (equivalent to clustering at the Mexican commuting zone level) are shown in parentheses. ${ }^{* * *} \mathrm{p}<0.01,{ }^{* *} \mathrm{p}<0.05,{ }^{*} \mathrm{p}<0.1$ 